van Tongeren, F., J. Beghin and S. Marette (2009), "A

Cost-Benefit Framework for the Assessment of Non-Tariff Measures in Agro-Food Trade", OECD Food, Agriculture and Fisheries Working Papers, No. 21, OECD Publishing, (C) OECD.

doi: $10.1787 / 220613725148$
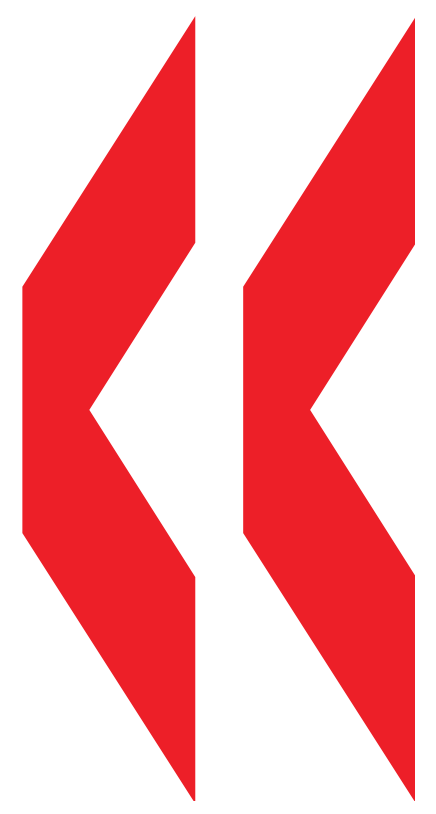

OECD Food, Agriculture and Fisheries Working Papers No. 21

\title{
A Cost-Benefit Framework for the Assessment of Non-Tariff Measures in Agro-Food Trade
}

Frank van Tongeren ${ }^{\star}$, John Beghin, Stéphan Marette

JEL Classification: F13, L15, L51, Q17 


\section{Foreword}

This report develops a conceptual framework for the assessment of costs and benefits associated with non-tariff measures that allows an evidence-based comparative assessment of alternative regulatory approaches. It was prepared by Frank van Tongeren (OECD Secretariat), John Beghin (Iowa State University), and Stéphan Marette (INRA), and benefited from contributions by Joanna Komorowska (OECD Secretariat).

\section{Keywords}

Information and product quality; standardization and compatibility, economics of regulation, agriculture in international trade, trade policy; international trade organisations. 



\section{Table of Contents}

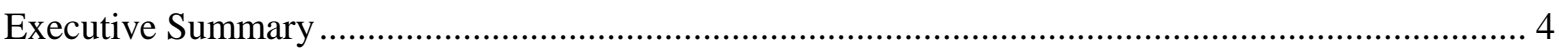

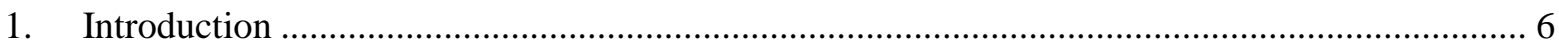

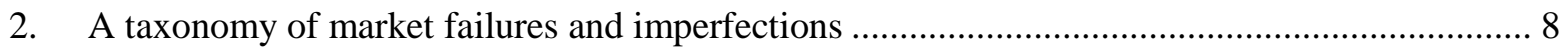

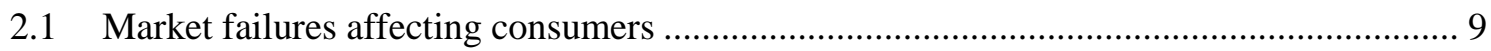

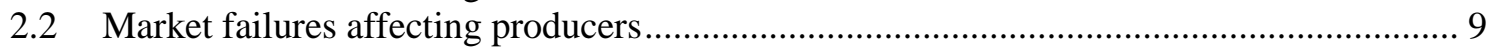

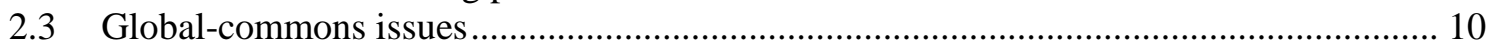

2.4 Imperfect monitoring and other government failures ............................................... 10

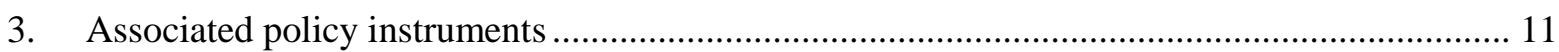

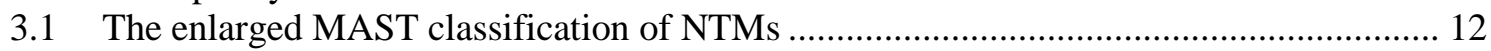

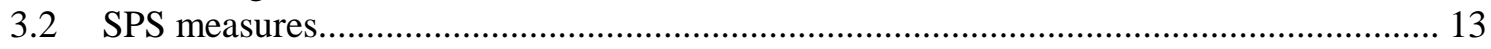

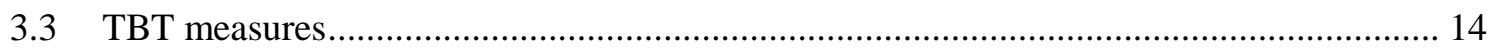

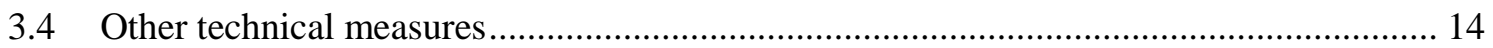

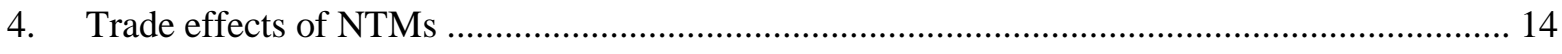

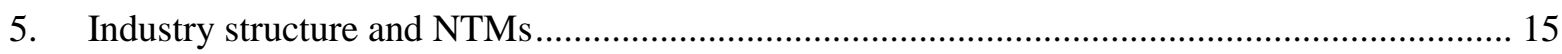

6. The use of cost-benefit analysis and alternative methods.................................................. 16

7. Cost-benefit framework: a modular approach ................................................................. 18

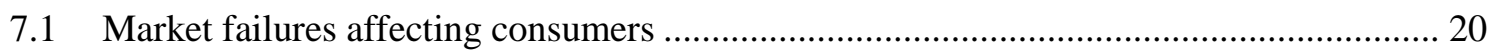

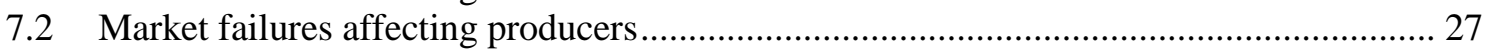

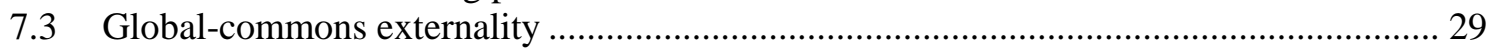

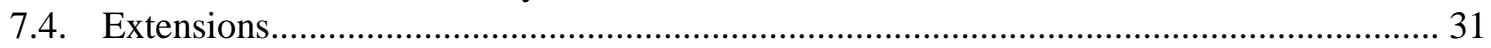

8. Recent advances in measuring valuation of market failures and global commons ................... 33

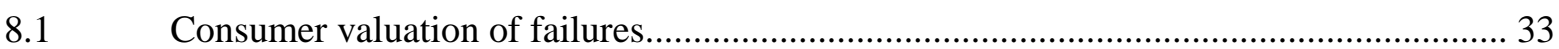

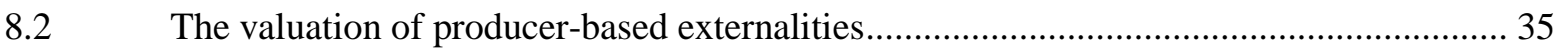

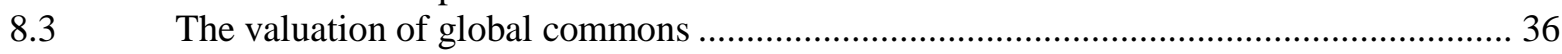

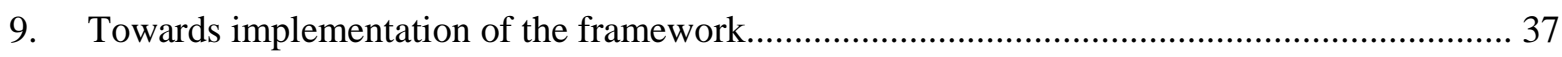

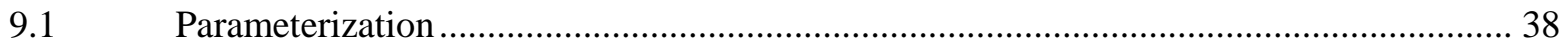

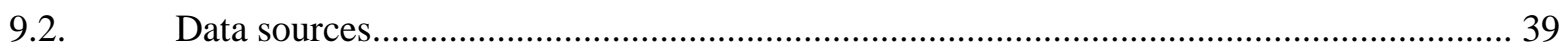

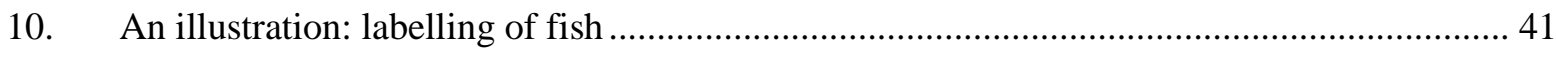

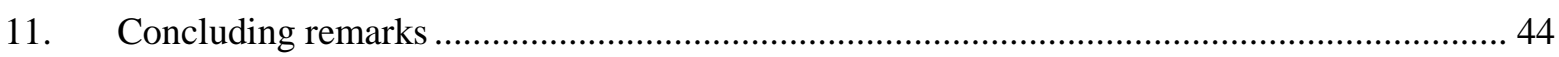

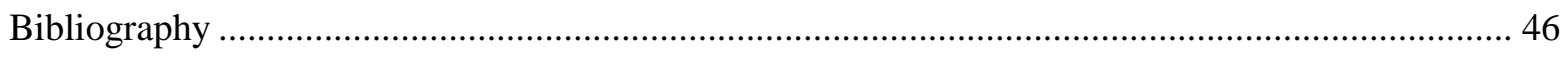

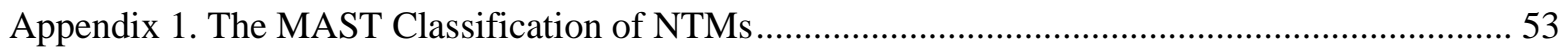

Appendix 2. Derivation of Market Equilibria and Welfare Measures ............................................... 69 


\section{Executive Summary}

Governments are increasingly called upon to respond to a variety of concerns raised by society in many areas such as the environment, animal welfare and food safety. Corrective actions are expected when markets either do not exist or fail and hence result in inefficient outcomes. If market solution is not satisfactory, governments have a number of options available to intervene, including regulatory, subsidy or tax based measures. Responding to some of those concerns is a purely local or national matter with little or no incidence on trade or trade policy. But in the case of traded goods, non-tariff measures (NTMs) are becoming an increasingly important policy tool particularly against a background of continued trade integration and lowering classical barriers to trade, such as tariffs and quotas.

Imports can carry invasive species such as pathogens, pests, or weeds, foreign to an economy's ecology. Different trade partners may have different food safety standards and institutional capacity to enforce these standards. This may lead to imports of food that do not meet domestic requirements. Imperfect and incomplete monitoring at the border where it occurs compounds the health or environmental risk. In countries with ill-defined property rights, trade may also encourage unsustainable production of some goods for the export market, leading to a deterioration concerning global-commons issues.

Assessing the economic effects of NTMs poses significant challenges. Many technical measures may restrict trade but improve welfare through reduction in negative externalities (e.g. through reduced risk of importing pests or diseases) or informational asymmetries (e.g. through a label providing to the consumers details on the product). Other measures can expand trade as they enhance demand for a good through better information about the good or by enhancing the good's characteristics.

Efficiency costs of NTMs are hence much less evident than the welfare losses associated with tariffs and quantity measures. They do not necessarily embody the economic inefficiencies that are associated with classical trade barriers, unless they discriminate between sources of supply, and they may be the least trade-restricting policies available in the face of market imperfections. It is therefore not clear a priori that the trade impacts of regulations are inefficient, or that removal of associated non-tariff measures that affect trade would achieve efficiency gains that would exceed the losses from weaker regulation.

The report develops a unified analytical framework to assess the costs and benefits of measures for stakeholders along the supply chain: domestic consumers, producers and governments, as well as foreign suppliers, and where relevant it can even include foreign consumers and governments. Trade effects are part of the assessment, as measures impact on trade as conduit of the externality, but trade effects are not the sole focus. The analytical framework allows comparison of alternative ways to design measures and discerns their trade and welfare effects. For example, an import ban (or prohibitive 
standard) to keep the domestic market free of some undesired product characteristic can be compared to allowing trade under the condition that the foreign product be clearly identifiable (e.g. through labelling).

The central notion of the framework is to distinguish those consumers (or producers) that are concerned by the negative or positive externality and product attributes, from those that are not concerned. The value that concerned consumers attach to avoiding the undesired product characteristic is a key variable in the cost-benefit assessment of measures that address failures affecting consumers. Estimating empirically this value is a challenge, but recent advances in consumer economics are promising. On the production side, the value of avoiding a failure is directly related to the value of the production loss that can occur if the failure remains unabated.

The cost-benefit framework is essentially a modular partial equilibrium model, with demand and supply relationships, that can be calibrated to empirical data and allowing the calculation of economic welfare effects. The modular set-up renders the approach flexible enough to expand it with side calculations. For example, detailed estimates of costs associated with monitoring and enforcement of measures could easily be added, but are not currently elaborated. The report also mentions several extensions that can be incorporated but are not fully discussed, such as non-prohibitive standards where both domestic and foreign firms make costly efforts to comply and consumers are to some extent able to identify the degree of compliance. Other extensions include entry and exit of firms in the face of fixed and variable compliance cost.

The proposed methodology is operational for comparing alternative policy choices like standards, border inspections policy and labelling in an international context. The methodology contributes to a more comprehensive welfare analysis of NTMs than that offered by looking at trade affects alone.

Application of the framework to specific issues will need to address limitations of the method developed here, especially when human health issues are concerned. For such cases, alternative methods have been briefly reviewed in this report and those could be applied. The empirical results will depend on the configuration of parameters and on the quality of data used. To determine the robustness of the results and to underline the limits a thorough sensitivity analysis with alternative assumptions, ranges of parameter values and different scenarios can be employed. Showing whether a conclusion is robust under a range of plausible parameters can be more valuable than one single positive welfare estimate.

The comparative approach to NTMs allows for the identification of alternative ways to address a given regulatory problem. By systematically enumerating costs and benefits for all the different economic actors involved, an evidence-based approach can be followed that yields a solid basis for mutual exchange and identification of least-cost solutions. 


\section{A Cost-Benefit Framework for the Assessment of Non-Tariff Measures in Agro-Food Trade}

\section{Introduction}

The German Reinheitsgebot ("purity law") for beer dating back to a Bavarian law of 1516 is a well known example of a set of rules that describe how a product meant for human consumption had to be produced in order for it to enter the market. The Reinheitsgebot was partly motivated by concerns about food safety, assuring that the right ingredients were used. ${ }^{1}$ Four and a half centuries later, the German insistence that beer had to be brewed according to this standard had to give way in the interest of freer trade on the internal market of the EU. Since the unilateral German standard has been abolished consumers can now enjoy beers from other European and non-European suppliers next to beer that is still produced under the old Reinheitsgebot.

This historical anecdote nicely illustrates the issues treated in this report. Regulations in the food and agriculture sector are put in place and enforced by governments in order to address societal interests where unregulated markets are not yielding the desired outcome. Many of the regulations address human health issues; others address environmental and animal welfare problems associated with agricultural production. As long as the regulation concerns a non-tradeable good (or service), the optimal design of the regulatory measures need not take the interest of foreign parties into account. Such was largely the case in the $16^{\text {th }}$ century beer market in Bavaria, which was very localized with very little cross-border trade. However, when the product is tradeable across national borders, border measures and behind-the border measures are usually taken to assure that the imported varieties meet domestic requirements. Banning all noncompliant products from the domestic markets, as was the case in the German beer market before the European Court of Justice ruling in 1987, is one very drastic instance of such a non-tariff measure (NTM).

With increased international integration, trade is increasingly becoming a vector of external effects, and governments have responded with a wide array of NTMs to the need to safeguard domestic concerns (Levine and d'Antonio, 2003). Imports can carry invasive species such as pathogens, pests, or weeds, foreign to an economy's ecology (CABI, various). Different trade partners may have different food safety standards and

1. Another motivation was to restrict the use of wheat in beer brewing so as to divert wheat into bread production. Next to the brewing ingredients (barley, hop and water) the law also regulated the sales of beer in terms of packaging requirements and pricing. Bavaria insisted on national acceptance of the Reinheitsgebot as a precondition for German unification under Otto von Bismarck in 1871. It became a Germany-wide law only in1907. The controversy over what may be called a proper "beer" in Germany continues to the present time. Another motivation was to restrict the use of wheat in beer brewing so as to divert wheat into bread production. 
institutional capacity to enforce these standards. This may lead to imports of food that do not meet domestic requirements. Imperfect and incomplete monitoring at the border where it occurs compounds the health or environmental risk. In countries with ill-defined property rights, trade may also encourage unsustainable production of some goods for the export market, leading to a deterioration concerning global-commons issues (Chichilnisky, 1994).

In some instances in which trade is the direct conduit of significant external effects, it may be an option to restrict trade, but some policies are more effective at addressing external effects than others. Many technical barriers to trade may restrict trade but improve welfare in the presence of negative externalities or informational asymmetries. Other measures can expand trade as they enhance demand for a good through better information about the good or by enhancing the good's characteristics.

The different forms of NTMs carry different costs and benefits for different parts of society. For example, banning non-compliant beers from the German market has benefited some domestic beer producers by excluding foreign competition, it may also have protected consumers from consuming unsafe ingredients, but it also deprived some consumers of access to foreign varieties of beer, once the technology was in place to make beer tradeable over longer distances.

This report develops a framework for a systematic accounting of economic costs and benefits of NTMs. By looking explicitly into potential benefits that NTMs may generate through addressing various types of market failures, this approach differs substantially from the recent literature on non-tariff barriers ${ }^{2}$, which tends to have a narrow mercantilist focus on foregone trade (e.g. Otsuki et al., 2001). The cost-benefit framework developed here allows for an economic assessment of different alternative ways to address the same market failures. Three broad classes of market failures are considered: 1) failures affecting consumers, such as imperfect information related to food safety, but also consumer concerns relating to production methods; 2) failures affecting producers, such as animal disease outbreaks; 3) global commons issues, usually related to the conservation of valuable eco-systems. Finally, we also touch upon the problem of limited monitoring of compliance with food standards.

A unified framework is developed that allows the assessment of economic effects of NTMs designed to address these different types of market failures. A central notion in this framework is to distinguish those consumers (or producers) that are affected by the market failure from those who are not, and to derive a method to empirically measure the benefits and costs associated with NTMs for these different groups. In practice the distinction between the two groups may be hard to make. On the consumer side, this approach rests on insights from modern empirical consumer economics and on the producer side it incorporates insights from epidemiological studies.

The framework incorporates different types of consumers distinguished by their concern for negative and positive external effects and product attributes. Their concerns may depend on the information they have on those product attributes. If domestic and foreign products have different product characteristics, some NTMs, such as compulsory labelling, can reveal the missing information and lead to a differentiation of consumer demand between domestic and foreign varieties. Foreign supply may also be a source of

2. Note that non-tariff barriers are a subset of the broader concept of non-tariff measures as used in this report, since it is not clear a priori whether a given measure in fact constitute a barrier to trade. 
negative externalities in production, such as the introduction of invasive species. The proposed framework captures those effects and the associated NTMs through their effects on cost of production of affected domestic producers. The proposed framework also addresses NTMs related to global commons issues.

The framework is modular, in the sense that new elements with detailed side calculations can be attached or removed from the main structure without the necessity to alter the general logic of the approach.

The overall objective of the work as defined in the scoping paper OECD (2007a) is to investigate the significance of NTMs covering agricultural and food trade and to quantify their economic impact. By aiming to develop a framework for economic assessment of selected non-tariff measures initiated by governments in the agri-food sector in OECD countries, the current report presents a first step towards an evidencebased approach that will yield a solid basis for mutual exchange and identification of least-cost solutions. The present report discusses a conceptual framework to facilitate a comparative assessment of different approaches to address a given market failure or imperfection through regulatory measures that have a bearing on international trade. The conceptual work is complemented by a number of empirical case studies that are identified using a data-driven selection procedure and that highlight strengths and weaknesses of the conceptual framework.

The report is structured as follows. We first review the major forms of market failures and imperfections in section 2. Section 3 describes policy instruments associated with the failures identified in section 2; section 4 describes their trade effects. Section 5 discusses potential changes in market structure induced by NTMs and associated costs of compliance. Section 6 discusses the use of cost-benefit methods compared to alternative methods. A proposed modelling approach is presented in section 6. The remaining sections provide guidance on how to empirically implement the proposed framework. Section 7 reviews recent developments in valuation of external effects. Section 8 explains how to implement the framework, which is illustrated in Section 9. The last section provides a potential roadmap for further development. Several Appendices provide supplementary information on NTMs (Appendix 1), and the modelling approach (Appendix 2).

\section{A taxonomy of market failures and imperfections}

This section discusses the major forms of market imperfections and market failures which are relevant for NTMs. Imperfect and failing markets lead to outcomes that are not efficient, and this is an important rationale for government intervention. A large proportion of NTMs attempt to remedy external effects. Externalities occur when some agent's utility or production depends on the choices made by other agents, who do not factor these external effects into their decision making. As a consequence, there are costs, or benefits, associated with the externality that fall on some agent but are not reflected in market valuations. It is useful to characterize an externality by its point of impact in order to organize the discussion. When the external cost or benefit arises in consumption it will be referred to as a consumption externality, while those where the impact arises in production will be called production externalities. As an example, consider harmful chemical residues that arise in production, but their possible health impact occurs on the consumption side; this type of externality will therefore be referred to as a consumption externality. 
Other market imperfections addressed through NTMs relate to the consequences of asymmetric information (one partner in a transaction knows more than the other) or imperfect information (not all consequences can be known). The informational problems can also conveniently be located as occurring at the consumer or producer side. They can also play a role in the context of monitoring of rules and regulation by governments.

The taxonomy starts with failures affecting the utility of consumers; then the reports looks at their counterparts in production, i.e. failures linked to production. This is followed by a discussion of global commons issues, and finally by a treatment of some issues related to imperfect monitoring.

\subsection{Market failures affecting consumers}

Externalities affecting consumers: This case involves the creation of a negative externality on agents not associated with production or consumption of the good. Consumers are affected by the external effect which is independent from their own consumption basket. If a good releases pollution during either its production or its consumption it may affect other persons who are not at all involved in producing or consuming that good. Consumer concerns about animal welfare is another example; here some consumers (or rather 'citizens') are concerned about the production methods, their welfare is affected regardless their own decisions to consume or not to consume meat produced from animals produced under certain conditions.3 Consumers could be disaggregated into consumers in the importing country and those in the exporting country as they may be affected differently.

Asymmetric information and health, safety, or nutritional value: This type of imperfection is associated with the purchase or the consumption of the good by a final consumer. The consumer derives a benefit from consuming the good but also bears a cost or benefit not exactly known to him via a health impact. Hence the perceived and true social costs of the good differ. If the producer is well-informed about the characteristics of the good, a situation of asymmetric information prevails. Some attributes, either experience or credence attributes, are unknown or uncertain to the consumer at the time of purchase and may decrease (as in the case of unhealthy ingredients) or increase (as in the case of nutritional benefits) the value of the good. There are also attributes that are unsafe to consume and could harm consumers. Recent examples of cases where asymmetric information can be associated with an undervaluation of health risks are outbreaks of E-coli and salmonella unknown to some consumers, in either the importing or the exporting country

\subsection{Market failures affecting producers}

Externalities impacting producers: external effects arise when the production process of a good is altered by external forces other than prices. Water pollution may impact fishery production for example. The pollution is generated either by consumption, production, or trade elsewhere or by the environment itself as in the case of soybean rust brought to the US by hurricanes. The resulting impact is a decrease in production or an

3. This case corresponds to damages from the externality which are "separable" from the market consumption. The externality affects the representative consumer's welfare but not directly her market consumption decision. By convention, economics treats citizens as consumers whenever citizens are not producers. 
increase in the cost of production either by loss of efficiency (farm yields fall) or by trying to abate the external effects (fungicide applications to eliminate some fungus). These occurrences may be non-rival (a whole region is hit by a FMD outbreak) or private (a single producer hit by pollution). Occasionally, externalities can be positive, such as new imported technological knowledge which is non-rival in the sense that it is available to most domestic producers.

Asymmetric information in production: producers, like consumers, may also suffer from asymmetric information and purchase inputs with unsafe attributes (e.g. seed-borne disease transmitted to a farmer may induce losses).

\subsection{Global-commons issues}

Global commons or common-pool resources refer to resources perceived as belonging to the (global) community and requiring collective stewardship. They are open access or common pool resources, for which property rights are not well defined or not defined at all. Examples of such global commons problems include unsustainable resource use in forest products, depletion of fish stocks through over-fishing, and agricultural production with negative ecological impacts. Consumers do not need to consume a specific good themselves to suffer the externality. However, consumers may benefit from consuming products certified as respecting the commons. Eco-labels and fair trade are well known examples of measures providing perceived benefits to consumers with global-commons concerns.

Although the analytical treatment of global commons cases will often be closely related to the treatment of externalities affecting consumers, it is worth distinguishing the former as an increasing number of trade frictions between OECD and developing economies are based on global commons issues and as interest in sustainable practices expands. Trade is often central: a good is imported from a source characterized by global commons issues or unsustainable practices. A NTM in the importing country may attempt to alleviate the global commons problem in the sourcing country.

\section{$2.4 \quad$ Imperfect monitoring and other government failures}

In practice, the implementation of existing regulatory policies can only be imperfectly monitored and incompletely enforced. In this sense governments are failing by not doing enough, and consequently this is sometimes called failure by omission. The limited institutional capacity to monitor and enforce regulations sometimes calls for additional interventions, or may necessitate policies that would not be welfare-optimal if monitoring were perfect. Mitigating the institutional deficiencies can have strong trade implications and bring costly policies. A failure to detect and contain FMD or BSE early can induce a collapse of trade if partners are closing borders as an emergency measure. If institutional capacity for border inspection is limited, a country might chose to designate just one port of entry for imports of certain food products, and this measure can lead to an additional trade cost. Other policy responses may be more cooperative when they can be planned, especially in the North-South context. For example, coordination of policies such as certification of South exporters by importing countries in the North providing the additional capacity missing in the exporting country (e.g. the EU assisting Latin American meat packers to meet EU food safety and phytosanitary standards).

In many countries, full traceability and monitoring may elude the authorities. Even the highly developed regulatory frameworks in OECD countries cannot completely 
prevent salmonella and E-coli outbreaks. Theoretically, optimum monitoring should equate expected cost and benefits of monitoring activities, and this often means that complete monitoring and total prevention would be excessively costly. The ability to effectively regulate the agri-food sector is generally more limited in low income countries that lack institutional experience as well as financial resources. If there is limited capacity to inspect and monitor the resulting "failure of omission" (the government is not doing enough) will exacerbate the issue of food safety and global-commons externalities, as consumers do not have information on process and product characteristics of the imported food they buy. In this context, private standards have emerged to pick up some of the tasks. (Fulponi 2006, Garcia Martinez et al., 2007).

\section{Associated policy instruments}

The market imperfections discussed above can be addressed through a wide range of policies, but this report concentrates on those policies that have a potential impact on international trade flows, singling out non-tariff measures. In a recent initiative the MultiAgency Support Team (MAST) ${ }^{4}$ that provides the technical work on behalf of a group of eminent persons that has been charged by the directors general of UNCTAD and the WTO with advancing work on non-tariff barriers has developed the following definition of NTMs:

Non-tariff measures (NTMs) are policy measures, other than ordinary customs tariffs, that can potentially have an economic effect on international trade in goods, changing quantities traded, or prices or both. (MAST, 2008)

This definition is broad and to a large extent uninformative as was the older nontariff barrier category (NTBs), as both NTMs and NTBs are defined residually by policies that are not tariffs.

This broad definition of NTMs does not imply a prior judgment as to their actual economic effect, appropriateness in achieving various policy goals, or their legal status under the WTO legal framework or other trade agreements. For the purposes of OECD work on NTMs, this has further been narrowed down (OECD, 2007a) by excluding measures that directly impact on prices and quantities (quotas, tariff rate quotas (TRQs), State Trading Enterprises (STEs), import licensing and anti-dumping measures), and to concentrate on the less researched group of measures that indirectly affect price and/or quantity through addressing other attributes of the goods being sold, typically through regulatory measures. The next section illustrates what kind of policy measures fall into this category.

4. Institutional members of MAST as of July 2008 are: Food and Agriculture Organization of the United Nations (FAO), International Monetary Fund (IMF), International Trade Centre UNCTAD/WTO (ITC), Organization for Economic Cooperation and Development (OECD/TAD), United Nations Conference on Trade and Development (UNCTAD), United Nations Industrial Development Organization (UNIDO), World Bank (WB), World Trade Organization (WTO). Observers: European Commission (EC). United States International Trade Commission (USITC), United States Department of Agriculture (USDA). The MAST is jointly coordinated by UNCTAD and World Bank. MAST reports to the Group of Eminent Persons, which is convened by the director general of UNCTAD. MAST submitted a first report in July 2008. 


\subsection{The enlarged MAST classification of NTMS}

The MAST group has developed a new classification system of NTMs, which considerably extends the original TRAINS classification used by UNCTAD to inventorize trade measures (See section 8 on TRAINS-WITS). A particular feature of this new classification is the separate inclusion of categories for SPS and TBT measures as well as provisions to include procedural obstacles (related to the implementation of measures, not the measures themselves). The classification is currently being tested by UNCTAD and ITC through pilot studies in seven countries, and the classification is likely to be revised in light of the experience gained in the pilot studies ${ }^{5}$. The classification system is primarily designed to accommodate the exhaustive cataloguing of existing policies; it is therefore as much as possible free of prior assumptions about potential effects of measures and it is in that sense not an analytical scheme. The main groups of the new MAST classification are the following (the full list with additional sub-categories is provided in Appendix 1):

A. Sanitary and phytosanitary measures

B. Technical barriers to trade

C. Other technical measures

D. Price control measures

E. Quantity control measures

F. Para-tariff measures

G. Finance measures

H. Anti-competitive measures

I. Export related measures

J. Trade related investment measures

K. Distribution restrictions

L. Restriction on post-sales services

M. Subsidies

N. Government procurement restrictions

O. Intellectual property

P. Rules of origin

The main headings of the classification of procedural obstacles are:

- Arbitrariness or inconsistency

- Discriminatory behaviour favouring specific producers or suppliers

- Inefficiency or obstruction

- Non-transparency

- Legal issues

- Unusually high fees or charges (e.g. for stamp, testing or other services rendered)

5. The case study countries are Brazil, Chile, India, Philippines, Thailand, Tunisia and Uganda. 
The subset of measures under categories (A) through(C) is most relevant for the current report. They have a relatively clear relationship with the market imperfections discussed previously. These broad categories also form the core of interventions which are on the rise worldwide (Beghin, 2006) and have common allocative effects. They increase cost of production via higher marginal cost or larger fixed cost, and they tend to affect industry structure. These types of instruments can also enhance consumer demand for goods by increasing quality attributes or by reducing informational asymmetries about the targeted good. Some of these policies jointly affect both producers and consumers. Many of the policies covered by categories (A) through (C) involve considerations of institutional capacity. Sometime they address capacity failures of trade partners (failure of omission by the exporting country); sometimes they imply an extensive domestic institutional capacity to implement policies. Although different types of requirements affect different inputs and stages of production, most of these policies increase cost of production either at the margin or via fixed cost.

The effects of price control measures under (D) are relatively well understood, and instruments types included in (E) have been extensively discussed with the analysis of quotas, tariff rate quotas and their administration (see for example OECD, 2002a, 2002b; Boughner, de Gorter, and Sheldon, 2000). Para-tariff measures included in (F) can be analyzed as conventional tax instruments and their incidence is straightforward to derive. The latter types of instruments could easily be added to the framework proposed below. The remaining categories $(\mathrm{G})$ through $(\mathrm{P})$ are also important but cannot easily be integrated in the proposed modelling framework. Procedural obstacles can, however, be translated into trade-cost which could be expressed as tariff equivalents in most cases, and could in principle be incorporated in to the framework proposed below.

\subsection{SPS measures}

Some SPS measures included in category (A) address asymmetric information between producers and consumers of products with credence attributes to ensure that buyers know what they buy and that it is safe either for human health or the environment. The standards and requirements target process and product attributes. SPS measures also address potential externalities in production via invasive species or infectious diseases. Most of the SPS policies under category (A) imply a shift in the marginal cost of production because additional costs are incurred to meet the requirements. In addition, some SPS measures may also increase and enhance demand by providing information to consumers.

Some SPS policies are directly linked to trade as the vector of the externalities. For example some interventions target foreign suppliers on a geographical basis. Category A280, geographical restrictions, is basically an import ban based on origin. Regulatory heterogeneity, i.e. the case where the exporter's standards are not in line with the importer's requirements, leads to a number of SPS measures. Certification requirements (A 310) address the institutional setting either domestically or abroad to ensure standards are met. A series of subcategories addresses the lack of reciprocity in certification and regulation when some standards, including international ones, are not recognized (see subcategories covered in A320, Lack of Recognition). 


\subsection{TBT measures}

These are regulations and standards targeting technical characteristics of products. As in the case of SPS, there are voluntary standards for both process and product attributes (B100 and subcategories). Both process standards and product standards shift cost curves by increasing cost of production, and they can impact positively on demand through reduction of asymmetric information between suppliers and consumers. Safer products are presumably more attractive to some or all consumers. Unlike SPS measures, TBT measures do not include explicit bans on imports from specific countries or regions.

Technical regulations (B200 and subcategories) cover compulsory standards and requirements. Again these concern product standards as well as process standards, presumably shifting supply leftward and demand to the right. These regulations address asymmetric information and opportunistic behaviour of suppliers regarding credence attributes. Traceability and origin of material are included in this category, as are limits on residues and restrictions on some substances (B230 subcategory). GMO regulations are another subcategory of B200, and so are identity preservation and environmentspecific requirements, addressing either production-based externality and/or commons issues.

Subcategory B300 covers conformity assessment, certification, and testing of products and the cases in which lack of recognition of certification procedures may hinder exchange. The latter is more in the realm of institutional or policy failures as discussed above.

\subsection{Other technical measures}

The third category of NTMs covers policies and requirements which somehow did not fit in the two previous ones but look quite similar to them for analytical purposes with some qualifiers. Sub-category C100 covers pre-shipment inspections to check conformity of the products, potentially addressing the above mentioned failure of omission; C200 covers custom formalities not included in (A) and (B). Finally C900 is the residual of last resort (technical measures n.e.s.). These are not obviously motivated by market imperfections.

\section{Trade effects of NTMs}

The prevailing economic approaches to analyze NTMs often provide a onedimensional effect of trade losses without a clear delineation of the link between forgone trade and welfare. From the outset, this project is designed to go beyond this type of approach and to comprehensively account for welfare implications of policies addressing externalities and market imperfections. Many NTMs may restrict trade but improve welfare in the presence of the negative externalities or informational asymmetries discussed above. Other NTMs can expand trade as they enhance demand for a good through better information about the good or by enhancing the good's characteristics. (Maertens et al. (2007); Maertens and Swinnen (2009)). In the presence of disease risks, well designed NTMs may allow for some limited amount of trade, while in the absence of measures, such as strict border inspections or restricting imports to products from a specific country or region within a country, no trade might take place at all.

There is also an implicit presumption in much of the existing literature that harmonization of NTMs is welfare improving. When harmonized, these regulations can 
reduce unit cost of production via economies of scale and can guarantee free movement of goods on a unified market, such as has happened in the EU. But consumer choice might also be reduced if the goods being harmonized are initially differentiated and if tastes differ across countries (Moenius, 2006). The case for harmonization is not settled yet with no consensus on policy prescriptions emerging from the analytical literature (Barrett and Yang, 2001; Casella, 1996 and Gandal and Shy, 2001). Much tension exists between theory and applied work in the literature on harmonization of NTMs. Many of the empirical assessments have been mercantilist focusing on forgone trade (e.g. Otsuki et al., 2001) rather than considering their potential welfare-enhancing effects.

As trade can be a vector for transmission of an externality, some NTMs directly address trade as the source of the externality, such as through a restriction or prohibition in the case of an outbreak of infection. Several papers have looked at these restrictions with animal disease outbreaks (Wilson and Anton, 2006; Lee and Paarlbergh, 1998; Pendell et al., 2007 among others).

Trade effects of NTMs have been extensively analyzed with the gravity-equation approach. Many gravity analyses tend to be broad in scope (multi commodity/sector, countries, and policies), which allows for a broad-brush investigation of general hypotheses such as the trade-restricting or expanding effects of NTMs or the impact of harmonization. The gravity equation has also been used to look at specific policy issues such as the EU aflatoxin policy (Otsuki et al., 2001). Most studies find some evidence of trade-impeding effects associated with technical measures using various indicators (levels, counts, AVE, price wedges). Beyond the well-established trade impeding effects of many SPS and TBT measures, trade expanding effects also have been identified, often through harmonization and shared standards, in customs unions, and for some goods and policies (Disdier et al., 2008; Fontagné et al., 2005; Henry de Frahan and Vancauteren, 2006; and Moenius, 1999, 2006). A few studies found an absence of trade effects from technical measures in some sectors (e.g. Fontagné et al., 2005) and for harmonized measures (Czubala et al., 2007). Effects of NTMs have also been studied with partial and general equilibrium simulation models, usually by parameterizing them as tariffequivalent in the import demand (or export supply) functions. See OECD (2008b) for a review of quantitative approaches.

\section{Industry structure and NTMs}

Compliance with NTMs has a bearing on producer costs, both variable (through additional activities) and fixed (through additional investments), and this can have important consequences for the industry structure. If compliance with standards and regulations implies large investments that are sunk once undertaken, economies of scale become an important characteristic of the industry. Sunk costs related to NTMs may become an entry barrier and a decisive determinant of industry structure. Not all firms will meet the new standards and the structure of an industry can profoundly change because of the new production requirements to satisfy in the export market. This is leading to concerns regarding market participation in low-income countries in particular. Often this unequal ability to meet standards causes dualism in the industry affected by the new regulatory environment. A modern and successful segment emerges, whereas smaller producers are marginalized and serve an informal domestic market, exit the market or become employees in larger firms (Rau and van Tongeren 2007; Maertens and Swinnen 2006, and others). 
The precise effect of the NTM on fixed and variable cost is important: changes in variable costs translate into changes in prices, and if all firms have to incur the same variable cost change in order to meet the NTM there is no obvious competitiveness effect. However, sunk investments do not figure in firms' optimal pricing decisions and have more indirect effects on market prices through entry and exit of firms. Only firms that are sufficiently productive to "jump the hurdle" of fixed market entry costs will be able to export (Melitz, 2003).

Measuring cost of compliance is far from straightforward. Various methods have been used: firm-level surveys (e.g. Wilson and Otsuki 2004b), price comparisons (Yue et al., 2006; Ferrantino 2006), cost accounting (e.g. Grothe et al., 2000), econometric estimations (Antle, 2000; Maskus et al., 2005).

The principal problem that needs to be addressed when measuring cost of compliance is the question of the correct baseline, or point of reference. In some cases producers would have made the production changes required to meet importer requirements even without standards being in place, or producers make further changes not directly necessary to achieve compliance. In these instances it is questionable whether the direct costs of such changes can be considered as compliance costs. Additional difficulties arise if exporters serve different markets with different requirements, perhaps leading to differing compliance costs across markets, and higher total compliance costs Harmonization can potentially reduce those costs.

\section{The use of cost-benefit analysis and alternative methods}

The objective of quantifying the economic effects of non-tariff measures can be addressed as a systematic assessment of costs and benefits of a hypothetical policy change. The question asked is: 'what are likely costs and benefits from changing the current policy?' The current policy may be a situation of no regulation or no interference with the market (do-nothing). The typical problem facing such an assessment is that some of the relevant cost and benefit items cannot be estimated with great precision - simply because the policy change is hypothetical and there are no empirical observations available that could reveal reactions of consumers and producers to the new policy set.

The literature on cost-benefit analysis has developed a number of approaches to deal with this particular measurement problem, and they are frequently used as a tool in policy making. Several OECD countries, such as Canada, some EU Member States and the US, provide official guidelines on how to carry out an exhaustive cost-benefit analysis for policy making, especially in the area of regulatory reforms. At the level of the EU official guidelines exists for cost- benefit assessments in a number of policy areas that are relevant across the entire EU. There are several reasons why cost-benefit analysis is widely considered (OECD, 2006c). First of all, it provides a rational basis for decision making by forcing the decision maker to consider the beneficiaries and losers of a policy change. Secondly, cost-benefit analysis requires any policy to be considered as one of a series of options. Thirdly, cost-benefit analysis helps to determine the optimal scale of the policy, in the sense of choosing the option that maximises net benefits. Moreover, when enumerating investment decisions a cost-benefit analysis explicitly accounts for time through a process of discounting. 
Being deeply rooted in the theory of welfare economics the cost-benefit analysis takes individual preferences into account. ${ }^{6}$ It translates the theoretical notion of preferences into an applied measurement of consumer choices through the willingness-topay (or willingness to accept) concept. Section8 below discusses recent advances in measurement of willingness to pay (WTP), and alternative applied methods.

Despite its appeal, various constraints may impede the realization of exhaustive cost-benefit analysis. These constraints range from the efforts necessary to collect information to the occurrence of effects that have an unclear or indirect impact on consumer preferences. But the main constraint is clearly the difficulty to monetize policy impacts that save lives. Individuals may be reluctant to place a monetary value, or express their willingness to pay, on a life saved. Two alternatives exist to circumvent the impossibility to elicit a willingness to pay in such cases that concern human life.

The first alternative method, the cost effectiveness analysis, avoids estimating the benefits of lives saved. Instead it compares alternatives on the basis of their costs and a single quantified, but not monetized, effectiveness measure. The classical example is the cost of different measures per statistical life saved (see for instance Morall, 2003). This approach puts more emphasis on the assessment of costs. If it is based only on the assessment of budgetary costs it may underestimate the full economic costs of a policy move.

The second alternative method is the QALYs (Quality Adjusted Life Years) approach, which is generally used in the medical and public-health field. The costs of alternative policies are compared to the health changes, measured over two dimensions: the quality of life (morbidity) and the length of life (mortality). Several alternative methods exist for estimating the costs of mortality and morbidity and evaluating in money terms the benefits of government action resulting in a reduction of sanitary risk. Statistical dose-effect methods are used to estimate the risk reduction. With the human capital method, a value is placed on the reduced risk of premature death based on an evaluation of discounted labour income flows. For an individual of a given age, the value of the statistical life prolonged by a regulation corresponds to the discounted sum of the mathematical expectation of the person's revenues (Freeman, 1993). With the cost of illness method, a value is placed on the reduced morbidity resulting from a regulation, based on an estimate of medical costs and productivity losses due to illness (Buzby et al., 1996). Opportunity costs from investing in activities that reduce the risk are included in the value of reduced illness (Landelfeld and Seskin, 1982). The main drawback of these approaches is their inability to reflect consumers' responses in demand and their indirect impact on producers. The costs estimated through QALYs methods are not mapped into demand adjustments linked to reactions of consumers. Consequently, they cannot take into account market price reactions and their concomitant impact on producers and consumers.

QALYs are generally used in the medical and public-health field, while WTP methodologies are the main instruments in transportation and environmental economics. See Hammitt (2002) for discussion and comparison of underlying key advantages and drawbacks of these two alternative approaches. For the analysis of NTMs both methods could in principle be used, depending on the specific case at hand. The CBA framework

6. Some may see this as a weakness rather than strength of cost-benefit analysis, because it implies that preferences should count, even if the holders of these preferences are not well informed. For full discussion see OECD, 2006c. 
with WTP measures can most efficiently be used if the market failure issues linked to NTMs relate to quality aspects that cannot be translated into clearly identifiable shortterm illness (such as the preferences for animal welfare, the origin of products, the protection of endangered species, negative preferences for GMOs).

Whatever method is used, there will always be limits to the precision and the scope of the measurement of costs and benefits. The use of different models that explain the same phenomenon may lead to different results. One way of dealing with that problem is to evaluate each model separately and then compare their results, perhaps by taking into account probabilities with which each model predicts its outcome (see for example Treasury Board of Canada, 2007).

\section{Cost-benefit framework: a modular approach}

This section introduces a framework to systematically assess costs and benefits of NTMs addressing the external effects and market imperfections discussed previously. The theoretical framework is designed to be applied with empirical data to facilitate a quantitative cost-benefit analysis. The objective of this section is to outline a common approach and its intuition. Not each and every potential effect is discussed here, as the framework may be easily extended in many directions to analyze particular trade problems. One element not elaborated here, but which can be important in practice, concerns costs related to administration, monitoring and enforcement.

The proposed framework is geared towards welfare analysis that can be calibrated and quantified based on information on real policy situations. The framework allows for a comparative analysis of welfare effects of different alternative ways, different NTMs, to address the same type of market imperfections. This is illustrated here by looking at only three polar cases: free trade; a prohibitive standard or an import ban; and free trade with labelling.

The framework comprises "modules" for calculation of cost and benefits affecting (a) domestic consumers, (b) domestic producers, (c) domestic government, and (d) foreign producers. For simplicity, foreign consumers and governments are not included here. In addition, the different actors in the supply chain (farmers, processors, retailers etc.) are collapsed into a single production stage representing supply. These abstractions influence results in many cases but are maintained here to preserve clarity in exposition. The framework distinguishes the external costs and benefits to various agents induced by failures and then cost and benefits to the same agents induced by policies imposed to remedy the failures.

A key feature of the framework is to distinguish those agents who are concerned by a given market imperfection from those that are not. On the consumer side, this involves distinguishing those consumers who have a preference for certain characteristics of the good in question (or a preference for avoiding certain undesirable characteristics) from those who are not concerned. This distinction may be difficult to make in practice, but will be vital in achieving an accurate outcome. Recent advances in consumer economics, and in particular experimental economics, offer ways to partition consumers into various groups by observing their choice behaviour. Similarly, on the producer side, a distinction is made between those who are affected by a producer based externality from those who are not. The exposition introduces a minimum of technical detail. The full derivations and calculations of welfare effects can be found in Appendix 2. 


\section{Table 1.Cases of NTM Analysis}

\begin{tabular}{|c|c|c|}
\hline Market failure & $\begin{array}{l}\text { Policy and } \\
\text { regulatory regime }\end{array}$ & Key feature and major likely outcomes \\
\hline \multirow[t]{3}{*}{$\begin{array}{l}\text { Consumption-based } \\
\text { externalities }\end{array}$} & $\begin{array}{l}\text { 1) Prohibitive standard or } \\
\text { import ban }\end{array}$ & $\begin{array}{l}\text { No competition from foreign producers Autarky but high quality. } \\
\text { Unconcerned consumers buy "too much quality". } \\
\text { Price paid is high with no imports. }\end{array}$ \\
\hline & 2) Free trade (no label) & $\begin{array}{l}\text { Foreign producers enter; larger supply, product is undifferentiated. } \\
\text { Consumers benefit from unique lower price; domestic producers lose from competition and lack of label. } \\
\text { Concerned consumers lose from imperfect information, lower average quality. }\end{array}$ \\
\hline & $\begin{array}{l}\text { 3) Free trade and } \\
\text { mandatory label }\end{array}$ & $\begin{array}{l}\text { Goods and demands are differentiated; } 2 \text { equilibrium prices. } \\
\text { Each consumer type can consume preferred product. } \\
\text { Consumers benefit from competition in supply. } \\
\text { Domestic producers have higher profit with higher price thanks to label. } \\
\text { Issues: who pays for labelling/certification, sunk or marginal cost of label, protectionist level of the label? Possible free-riding for } \\
\text { separable externalities. }\end{array}$ \\
\hline \multirow[t]{3}{*}{$\begin{array}{l}\text { Production-based } \\
\text { externalities }\end{array}$} & $\begin{array}{l}\text { 4) Prohibitive standard or } \\
\text { import ban }\end{array}$ & $\begin{array}{l}\text { The prohibitive standard or import ban precludes imports of foreign units that can contaminate domestic supply. No externality in } \\
\text { production. } \\
\text { Demand is independent of the externality. }\end{array}$ \\
\hline & 5) Free trade (no label) & $\begin{array}{l}\text { Foreign supply (imports) contaminates domestic production. Pivot of the domestic supply curve from higher cost of production } \\
\text { induced by externality. Total supply meets demand at lower price. Consumers gain as the price is lower than under autarky. } \\
\text { Domestic producers lose from lower price and higher cost. }\end{array}$ \\
\hline & $\begin{array}{l}\text { 6) Free trade \& } \\
\text { mandatory label }\end{array}$ & $\begin{array}{l}\text { Not analyzed here. A non-prohibitive standard could eliminate the externality, would increase the unit cost of foreign suppliers. } \\
\text { Consumers would benefit from the competition in supply. Producers would lose from competition but not from higher cost. The } \\
\text { price would be lower than under autarky }\end{array}$ \\
\hline \multirow[t]{3}{*}{$\begin{array}{l}\text { Global commons, } \\
\text { separable, non-rival } \\
\text { externalities }\end{array}$} & 7) Prohibitive standard & $\begin{array}{l}\text { Conceptually similar to case one when consumers do not have the information on the negative attributes. No feedback effect on } \\
\text { demand because externality is separable from consumption. The prohibitive standard eliminates the domestic part of the } \\
\text { externality but not the part generated outside of the country. Welfare improves as the externality is smaller. Price paid is relatively } \\
\text { high. }\end{array}$ \\
\hline & 8) Free trade (no label) & $\begin{array}{l}\text { Concerned consumers are not informed about the link between consumption and externality. Externality expands. } \\
\text { No feedback from the externality on demand. Free trade lowers the price paid but expands the externality. } \\
\text { Domestic producers lose; domestic consumers gain from lower prices but some consumers lose from expanded externality. }\end{array}$ \\
\hline & $\begin{array}{l}\text { 9) Free trade \& } \\
\text { mandatory label }\end{array}$ & $\begin{array}{l}\text { Not analyzed in this report. No feedback on demand but separable externality decreases as unit purchases have to meet the } \\
\text { standard linked to the label. If label is costly at the margin, supply pivots leftward and equilibrium price is higher. Potential free- } \\
\text { rider problem. }\end{array}$ \\
\hline \multicolumn{3}{|l|}{ Additional cases } \\
\hline $\begin{array}{l}\text { Non-rival global } \\
\text { commons } \\
\text { Non-prohibitive } \\
\text { standard and costly } \\
\text { effort }\end{array}$ & $\begin{array}{l}\text { 10) (not analyzed in this } \\
\text { report) }\end{array}$ & $\begin{array}{l}\text { Conceptually similar to consumer-based externalities (case 1) but even with proper policy and fully informed concerned } \\
\text { consumers, externality remains as some goods purchased by unconcerned consumers or in other countries will contribute to the } \\
\text { global externality. Potential free-rider problem. } \\
\text { Firms exert effort to abate the negative externality with some sunk and marginal cost of effort. Higher marginal cost is passed on } \\
\text { to consumers. A relatively large sunk cost influences the number of domestic and foreign firms (via entry and exit). }\end{array}$ \\
\hline
\end{tabular}

OECD FOOD, AGRICULTURE AND FISHERIES WORKING PAPERS No21 @ OECD 2009 
An important simplification is made in order to keep the exposition as straightforward as possible. In the discussion below it is assumed initially that the only source of the market failure is foreign and that the domestic economy is free of all production and consumption failures. Implicit in this approach is the assumption that domestic producers and consumers have fully adjusted their behaviour to internalize all externalities that might previously have existed, perhaps in response to domestic regulation. This simplification is merely introduced in order to keep the exposition tractable. It is relaxed later to analyze the more common case where both domestic and foreign producers are subject to production requirements (mandatory or voluntary standards), but domestic and foreign suppliers have to make different efforts to meet the different requirements on different markets. It is of course conceivable that the externality could originate domestically and be exported by the domestic country. Positive externalities are also possible, such as technology transfers. These cases are not considered here but could be accommodated in the framework. The following table summarizes the cases distinguished and highlights the main results.

\subsection{Market failures affecting consumers}

The market good being analyzed is assumed to be homogenous (i.e. same quality attributes) except for a specific characteristic that differs according to the country of origin. We assume that foreign producers offer a good with a specific characteristic (an environmental or safety risk or a specific process of production) that some domestic consumers do not want or do not favour, while the other domestic consumers are indifferent. This assumption matches the prevailing practice in which a regulation is supposed to protect some concerned domestic consumers regarding a characteristic conveyed by foreign products. This is clearly a simplification, as it is likely the case that both domestic and foreign producers are subject to mandatory standards in their home economies. However, this analytical simplification allows a sharper focus on the implications of differing requirements between countries, reflecting differences in what is considered appropriate product characteristics. Given these differing requirements, different levels of effort are required by domestic and foreign firms to comply with production requirements in different markets.

It is assumed initially that foreign producers are not able to correct this characteristic or to reduce the externality linked to the good they offer. Except for the one special characteristic, all consumers have the same preferences regarding the direct utility linked to the product. The characterization of preferences largely follows Polinsky and Rogerson (1983). Demands are derived from quadratic preferences, and supply is derived from a quadratic cost function. Turning first to consumer preferences, demand of each consumer $i=\{1, \ldots, N\}$ is derived from a quasi- linear utility function that consists of the quadratic preference for the market good of interest and an additive numeraire:

$$
U_{i}\left(q_{i}, w_{i}\right)=a q_{i}-\bar{b} q_{i}^{2} / 2-\operatorname{Ir}_{i} q_{i}+w_{i},
$$

where the term $a q_{i}-\bar{b} q_{i}^{2} / 2$ is the immediate satisfaction of consumer $i$ from consuming a quantity $q_{i}$ of the good and $w_{i}$ is the numeraire good consumed by $i$. For simplicity $a, \bar{b}$ are the same for the $N$ consumers.

The effects of externalities and information are captured by the term $-\operatorname{Ir}_{i} q_{i}$. The parameter $I$ represents the knowledge and/or externality context regarding the specific 
characteristic brought by the foreign product. If consumers are not aware of the specific characteristic or if there is an unaccounted externality linked to the specific characteristic, then $I=0$.Conversely, $I=1$ means that consumers are aware of the specific characteristic and can unambiguously identify the foreign product or they internalize the externality and reduce their consumption. The perceived damage associated with the consumption of the good with the specific characteristic is denoted $-r_{i} q_{i}$.

The maximization of the utility function under a budget constraint yields a demand function for each consumer. Aggregate demand for the good is obtained by summing individual demand functions over all $N$ consumers. However, total demand can be partitioned into two groups: those who are indifferent and those who are concerned about a specific characteristic of the good (see appendix 2 for details). Let the proportion $\beta=N_{l} / N$ of consumers be completely indifferent to the specific characteristic, with $r_{i}=0$ for every $i=1, \ldots, N_{l}$. In other words, they attach no damage value to consuming the good. The remaining proportion $(1-\beta)=1-N_{l} / N$ of concerned consumers is reluctant to consume the specific characteristic and associates a damage per unit consumed equal to $r_{i}=r_{2}$ for every $i=N_{l}+1, . ., N^{7}$. With $b=\bar{b} / N$, the (inverse) demand functions for the two subgroups become:

$$
\begin{cases}p_{1}^{D}(Q)=a-(b / \beta) Q & \text { indifferent consumers } \\ p_{2}^{D}(Q, I)=a-I r_{2}-[b /(1-\beta)] Q & \text { concerned consumers }\end{cases}
$$

Note that this specification is a mixed version of horizontal product differentiation (at the same price consumers are indifferent between a product with the characteristic and a product without the characteristic) and vertical product differentiation (at the same price concerned consumers unanimously choose the product without the negative characteristic). For food safety, if consumers unanimously prefer safe food, the specification can be captured with a full vertical product differentiation model where the proportion of indifferent consumers is $\beta=0 .{ }^{8}$

On the supply side, a perfectly competitive industry with price taking firms is assumed for both domestic and foreign supplies. There are $M_{\mathrm{O}}$ domestic firms and $M_{\mathrm{F}}$ foreign firms. Firms' cost functions are quadratic in output, and they are choosing output to maximize profits:

$$
\pi_{s j}=p q_{s j}-1 / 2 c_{s} q_{s j}^{2}-K_{s} \text { for } j=\left\{1, \ldots, M_{s}\right\} ; s=\{O, F\}
$$

7. The case where consumers attach a positive value to the characteristic is completely symmetric. It is captured by taking a negative value for $r 2$.

8 The demand functions given by (2) are linear, which is obviously a simplification. An alternative specification could be to consider non-linear demand with $p_{2}=\left[\frac{Q}{\beta\left(1+I r_{2}\right)^{\phi}}\right]_{\text {, where }}^{\frac{1}{\varepsilon}}$ is the information elasticity and $\varepsilon$ is the price elasticity of demand. The welfare estimations under both specifications are close when the price elasticity of demand is relatively low, which is often the case for food. 
where $c_{s}$ is the variable cost parameter and $K_{s}$ is the sunk cost linked amongst others to the firm's market entry and compliance with regulations. The profit maximization yields individual firm supply functions which can be added up to yield industry supply $Q^{9}$ :

$$
\begin{array}{ll}
p_{O}^{S}\left(Q_{O}\right)=c_{O} Q_{O} / M_{O} & \text { inverse domestic supply } \\
p_{F}^{S}\left(Q_{F}\right)=c_{F} Q_{F} / M_{F} & \text { inverse foreign supply }
\end{array}
$$

The total inverse supply defined by the sum of foreign and domestic supply is

$$
p_{O+F}^{S}\left(Q_{O}\right)=\frac{c_{O} c_{F} Q_{O}}{c_{O} M_{F}+c_{F} M_{O}} \quad \text { inverse overall supply }
$$

For the rest of the analysis it is assumed that $c_{O}>c_{F}$, which means that domestic producers incur higher marginal cost than foreign producers. This reflects a situation where domestic production incurs a costly effort to eliminate the specific characteristic (an environmental/safety risk or a specific process of production) that some domestic consumers do not want, while foreign producers do not have to bear these addition al costs. Alternative assumptions are easy to accommodate in the framework. To simplify further it is assumed initially that sunk costs $K_{O}$ and $K_{F}$ are equal to zero; this means that firm exit and entry can be ignored. This assumption will be relaxed subsequently.

Three regulatory configurations are compared in the sequence: $(i)$ a prohibitive standard impeding foreign products with the given characteristic (equivalent to an import ban), (ii) a free trade situation and (iii) a free trade situation with a mandatory labelling regarding the negative characteristic offered by foreign firms. The case with a positive label on the domestic product to signal the absence of the undesired characteristic is not detailed here, but the results would be technically similar to the situation (iii) where only the foreign product is labelled.

\section{Prohibitive standard}

The autarky situation brought about by a prohibitive standard is the easiest case to analyze. In this case, the overall domestic demand collapses to just one function, since the foreign product is simply not available. Figure 1 shows domestic demand (D) and domestic supply $\left(S_{O}\right)$. The price is located on the vertical axis and the quantity is shown along the horizontal axis. With zero imports, there is a single equilibrium price $p^{A}$ clearing the market by equalizing demand and supply with an equilibrium quantity $Q_{A}$ (such that $\left.p^{D}\left(Q^{A}, 0\right)=p_{O}^{S}\left(Q^{A}\right)\right)$.

The profits of all domestic producers correspond to area $O A p^{A}$ in Figure 1, and the surplus of domestic consumers corresponds to area $A p^{A} a$. Total domestic welfare is the sum of consumer and producer surplus and given by area $O A a$. Full analytical expressions for equilibrium values of prices and quantities as well as for all the components of welfare are provided in Appendix 2.

9. Individual supply functions are only defined for prices exceeding average costs, because otherwise firms would obviously cease production. 
Figure 1. Consumption externality, prohibitive standard

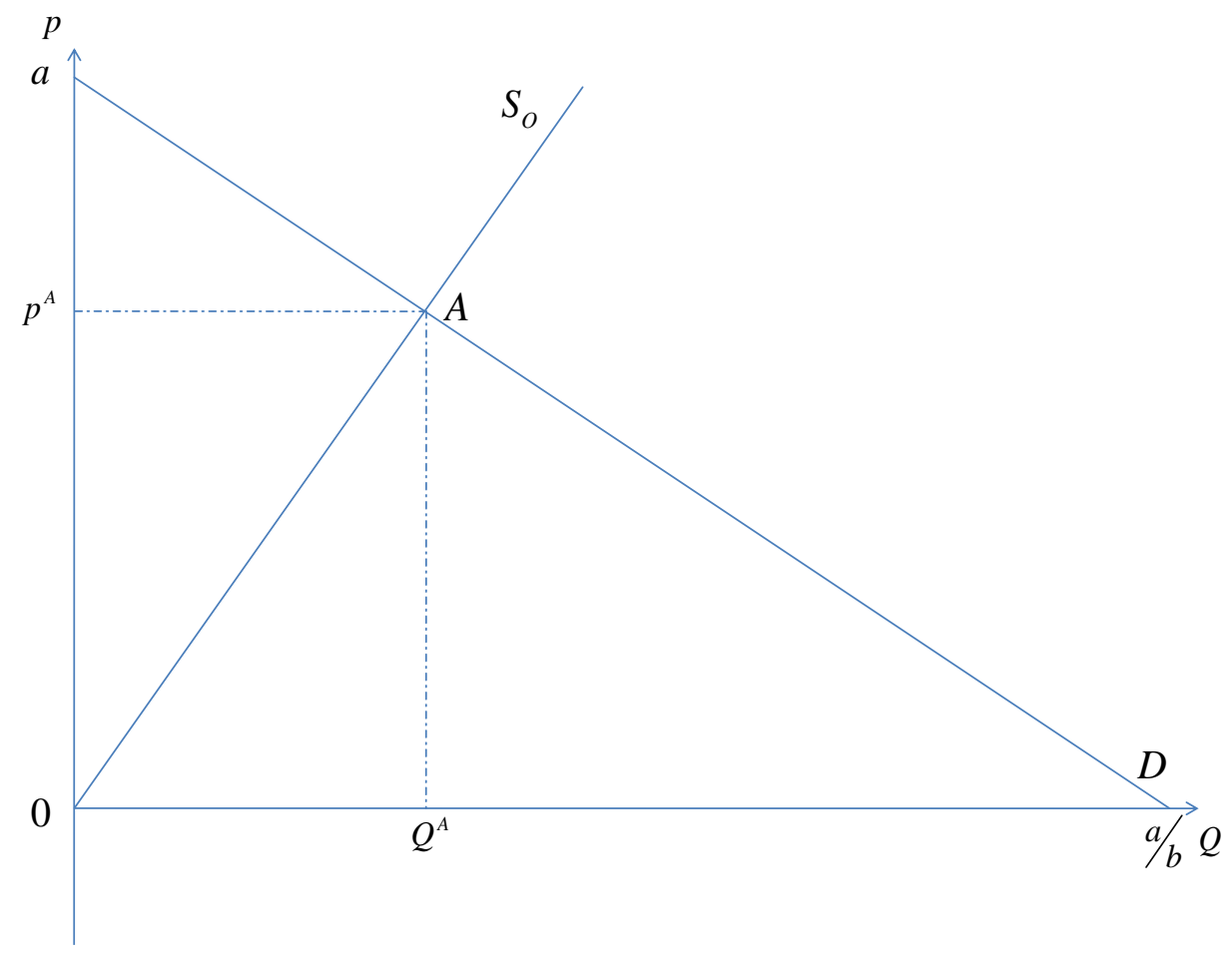

Free Trade

The case opposite to prohibited imports is free trade. This situation is represented in Figure 2, where the previous situation under autarky is now represented with dashed lines. Opening borders to foreign products (with a supply denoted $S_{F}$, ) changes the market allocation. The overall supply is represented by $S_{O}+S_{F}$ in Figure 2.

On the demand side, recall that a proportion $\beta$ of consumers is completely indifferent between domestic and foreign products, since these consumers are not concerned by the additional characteristic brought by the foreign producer. This subgroup has an overall demand $D_{1}$. A proportion $(1-\beta)$ of consumers is concerned by foreign products (for instance for safety/environmental, ethical, social reasons). Their willingness to pay for a given quantity decreases by $r_{2}$ for products with the given negative characteristic. $^{10}$ Therefore, the demand by concerned consumers becomes $\tilde{D}_{2}$ (defined by $\left.p_{2}^{D}(Q, 1)\right)$.

For this free trade configuration without labels, the overall demand is $D_{1}+\tilde{D}_{2}$ in Figure 2. The per-unit damage $r_{2}$ implies a kink in the aggregate demand schedule at the point $v$ in Figure 2. Under this configuration, there is a single market clearing price, since

10. Consumers' knowledge is simplified: we abstract from search or experience strategies. We also abstract from quality/safety signaling (via brand investment or guarantee) and/or firm's reputation in a context of repeated purchases under imperfect information. Rational expectations about quality require consumers to know all parameters (common knowledge) in signaling models. This requirement is unrealistic when technical expertise is required to know some attributes. 
the absence of information about the product characteristic makes it impossible to distinguish the two qualities and to segment the market. Market clearing leads to the equilibrium price $p^{B}$ such that demand equalizes supply and determines equilibrium quantity $Q^{B}$.

Figure 2. Consumption externality, free trade

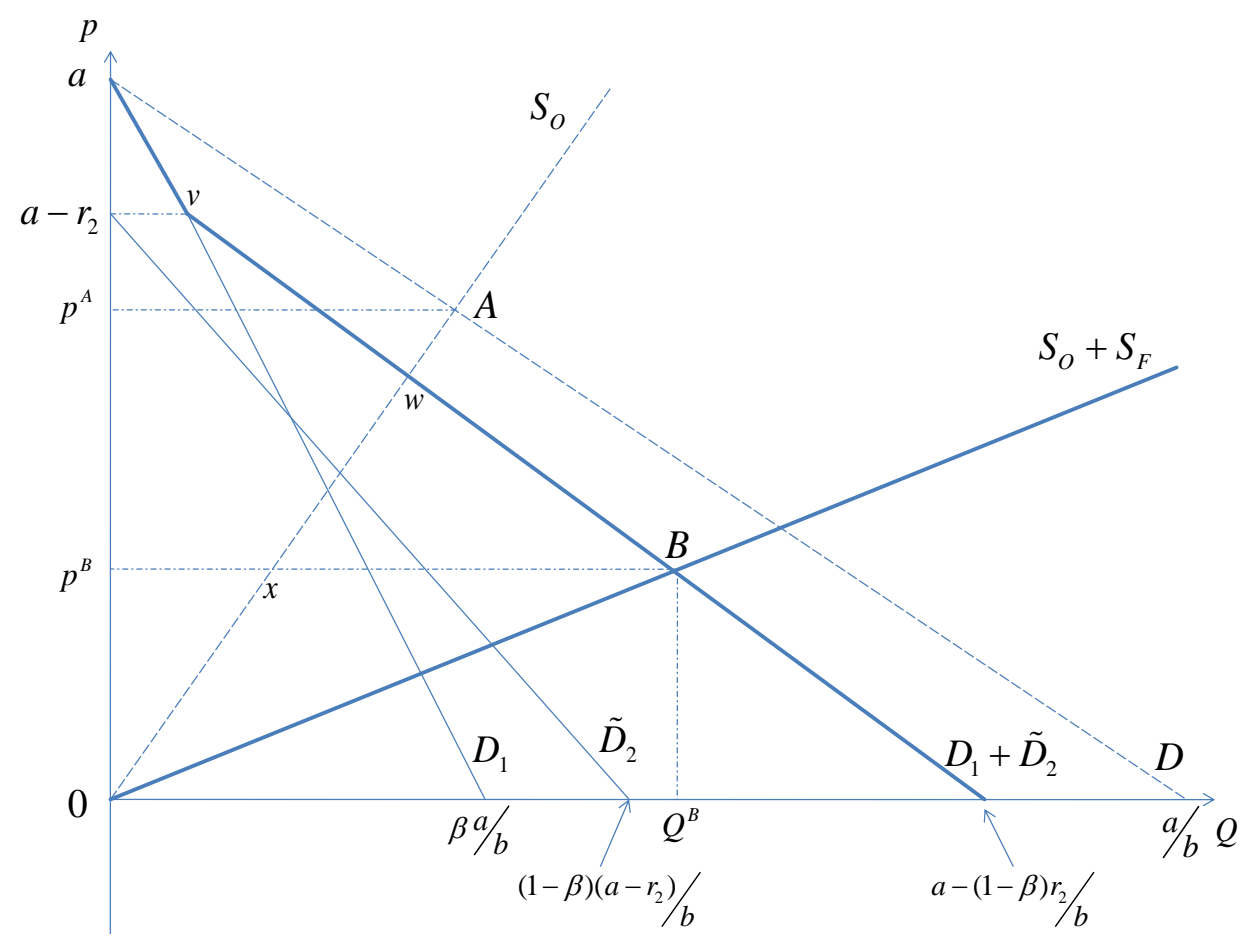

The profits of domestic producers correspond to area $O x p^{B}$ in Figure 2. Clearly, domestic firms earn less profits compared to autarky: $O x p^{B}<O A p^{A}$. The surplus of domestic consumers corresponds to area $p^{B} B v a$, and total domestic welfare is given by area $O x B v a$. The profit for foreign producer is $O x B$. Clearly, foreign producers benefit from trade liberalization compared to autarky with zero profit.

Figure 2 also depicts the changes in domestic welfare when shifting from autarky to free trade. Two opposite effects can be identified. The first one is caused by imperfect information for the proportion $(1-\beta)$ of concerned consumers who are reluctant to buy foreign products. Since these consumers cannot differentiate between the two types of goods, they decrease their demand at any given price and their surplus decreases. The second effect is the decreasing price effect coming from the supply increase linked to the foreign producers' entry.

The effect of trade liberalization on the domestic country, i.e. the comparison between the welfare $O A a$ under autarky and the welfare $O x B v a$ under free trade is ambiguous. If area $x B w$ is larger than area $v a A w$, the decrease in price is large enough for trade liberalization to be beneficial to the domestic country. Alternatively, area $x B w$ could be lower than area $v a A w$, when trade liberalization involves a relatively large decrease in the demand by the proportion $(1-\beta)$ of concerned domestic consumers. In this case trade liberalization would result in welfare losses, for the domestic country, and a trade ban 
linked to a standard that impedes foreign products with the specific characteristic would be preferred from a domestic point of view. Foreign producers will be injured by such a decision with a loss equal to $O x B$.

\section{Free trade with a mandatory label}

The free trade option may lead to a decrease in domestic welfare if the proportion of concerned consumers is large enough and, because of imperfect information about the good's characteristics, they reduce their demand sufficiently to offset the benefits obtained through cheaper imports. The third configuration combines free trade with a mandatory label that perfectly signals the negative characteristic linked to the foreign product. For simplicity, this label is understood by all consumers and fully transmits the relevant information to consumers. ${ }^{11}$ To simplify further, it is assumed here that labelling is costless; an assumption that can easily be relaxed. Labelling makes it possible to segment the market into two varieties: one foreign variety that contains the characteristic that is disliked by some consumers and the domestic variety that is free of the characteristic. It is assumed that the segmentation is perfect and that no arbitraging sales between the two segments can occur. The foreign supply $S_{F}$ is now represented in Figure 3. The previous situation under free trade without label is now represented with dashed lines (with the previous equilibrium situation at point B).

\section{Figure 3. Consumption externality, mandatory label}

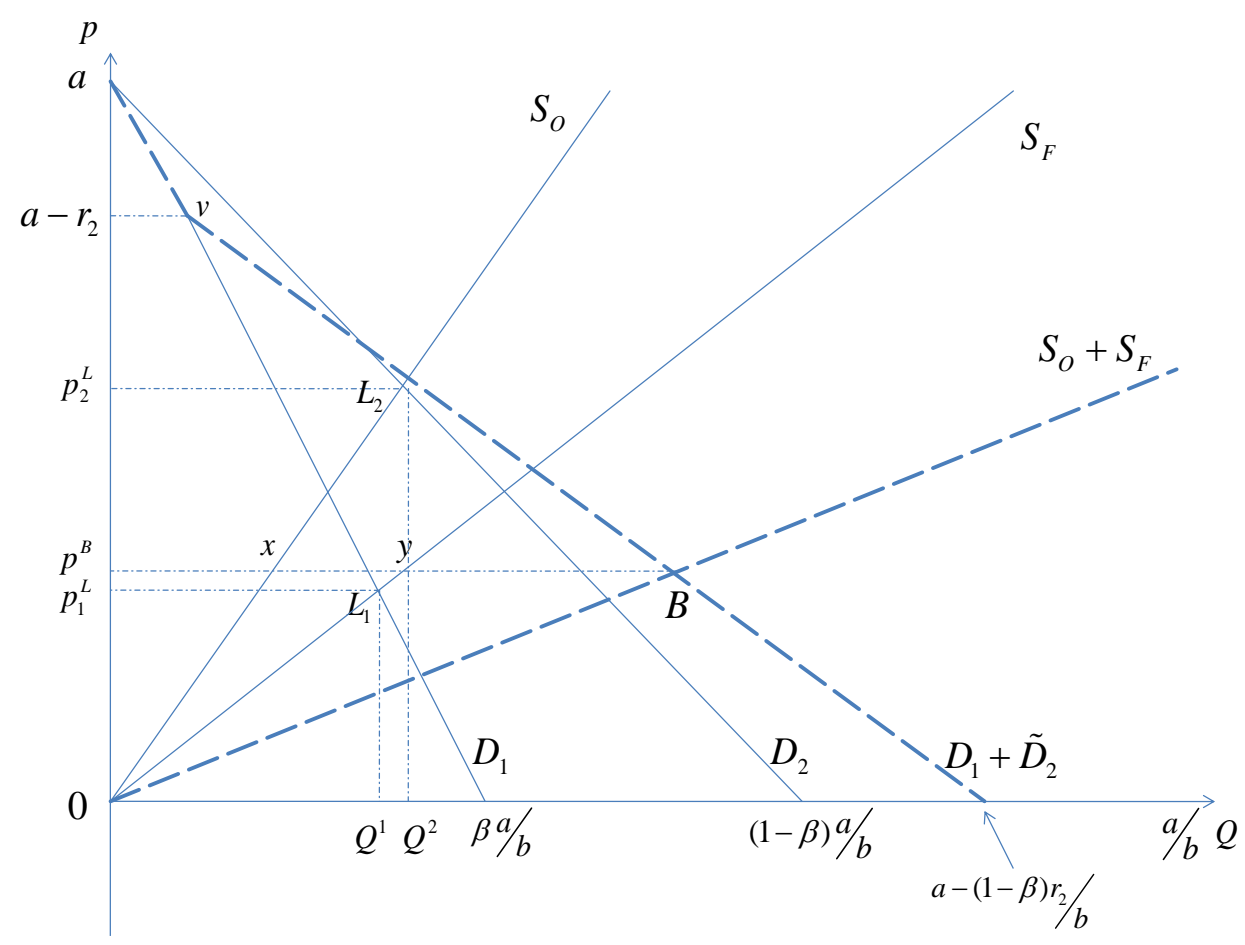

11. Wansink et al. (2004) analyze the limitations of labels to convey information. Some quality characteristics described in labels may be difficult for consumers to understand. Some labels may confuse consumers and tarnish the credibility of "better" labels. 
With labelling there are two prices clearing the market, since the label makes it possible to identify the two qualities by segmenting the market. The proportion $(1-\beta)$ of concerned consumers may now turn to the domestically-produced product without the negative characteristic, so that the demand $D_{2}$ is the same as under autarky with $p_{2}^{D}(Q, 0)$.

The first equilibrium price $p_{1}^{L}$ equalizes $p_{1}^{D}(Q)$ and $p_{F}^{S}(Q)$, where foreign products are bought by the proportion $\beta$ of indifferent consumers searching for the lowest price. The indifferent consumers' surplus is $p_{1}^{L} L_{1} a$ and the foreign producers' profits are $0 p_{1}^{L} L_{1}$. The second equilibrium price $p_{2}^{L}$ equalizes $p_{2}^{D}(Q, 0)$ and $p_{O}^{S}(Q)$, where the domestic products are bought by the proportion $(1-\beta)$ of concerned consumers who avoid foreign products. The concerned consumers' surplus is $p_{2}^{L} L_{2} a$ and the domestic producer's profits are $0 p_{2}^{L} L_{2}$. Domestic producers increase their profits compared to the free trade situation without label (the profit was $0 p^{B} x$ ).

Domestic welfare is area $p_{1}^{L} L_{1} a+0 L_{2} a$ in Figure 3. Under this third policy scenario, welfare is greater than that obtained under free trade without labelling measured by OxBva. The labelling policy allows higher profits for domestic firms and more product diversity for consumers. The latter is welfare improving compared to the free trade situation without the label. From the consumers' point of view, this situation is the best one, since a label provides information and trade liberalization helps to decrease prices.

The profit for foreign producers with labelling is $0 p_{1}^{L} L_{1}$, which is clearly lower than the welfare $0 p^{B} y$ obtained under free trade without a labelling requirement. Imposing a mandatory label is controversial between the two countries as foreign producers would lose some profits.

The welfare conclusions emerging from the above analysis depend obviously on the configuration of parameters. Demand elasticities and the size of the consumer's valuation of the externality $\left(r_{2}\right)$, determine the final assessment, and these will have to be determined empirically. Also, if domestic firms happen to have lower marginal cost then foreign suppliers, and can hence offer their product at lower prices than foreign suppliers, even non-concerned consumers will be tempted to buy domestic. Such cost differences can also be the result of the policy itself.

Obviously, the label enforcement leads to private and public costs related to the certification of products and production facilities, identity preservation and the promotion of the label (see Bureau et al., 1998). Labelling also increases production costs, as production and packaging processes have to be altered (for the example of costs and benefits of country of origin labelling for fruit juices see Centre for International Economics (2006)). If these costs are not "too" high (not prohibitive), the government will find it optimal to impose the label.

The incidence of labelling costs is a complicating factor. The optimal partitioning of costs between consumers, taxpayers, producers and the government depends on the nature of inspection and certification costs (see Crespi and Marette, 2001). If both domestic and foreign firms incur the same inspection and certification costs that depend on quantities, economic theory suggests that they are factored into consumer price. In this 
case, there is a parallel upward shift of both supply curves $S_{O}$ and $S_{F}$ in Figure 3. In contrast, if firms incur inspection and certification costs that are sunk, these costs are not directly incorporated in the price and firms cannot pass them on to consumers. Some firms may exit the market until the remaining firms break even with a higher market price at the new equilibrium. In this case, both supply curves $S_{O}$ and $S_{F}$ rotate towards the vertical axis in Figure 3. In this case the analysis should track the respective number of domestic and foreign firms. Whatever the type of cost, the higher the cost of certification and inspection is, the lower the benefit of imposing a mandatory label.

The potential for controversy between countries when considering policy options is exacerbated when investment costs are borne by foreign producers. Indeed, as these costs are not passed on to consumers directly in the price, it is optimal for a government to shift the sunk costs of labelling to foreign producers. A prohibitive cost may deter foreign producers from entering the domestic market and may become a trade barrier.

The labelling policy analyzed in this example did not discuss the type of label. Information about product characteristics can be provided in the form of "negative" labelling that marks a product as containing characteristics that are not desired by some consumers. Alternatively, "positive" labelling highlights in an affirmative way the compliance with a production standard. For the logic of the analysis pursued here the distinction does not matter, as long as the consumer is able to fully distinguish between different product varieties, but in terms of implementing a labelling policy there may be important differences between the two approaches. Consumers may react differently to a negative signal compared to a positive one.

\subsection{Market failures affecting producers}

Production-based failures, such as animal or plant disease outbreaks, can be conceptualized as a negative shock on supply as shown in Figure 4, inducing a shift or a pivot of the marginal cost curve. This follows Orden and Romano (1996), Wilson and Anton (2006), and Peterson and Orden (2008). The initial supply $S_{O}$ under autarky is represented by the dashed line in Figure 4. Consumer demand $D$ is assumed unaffected by the trade regime.

With the import of foreign products, the externality is transmitted to the domestic market and negatively impacts domestic supply with a shift from $S_{O}$ to $\bar{S}_{O}$. This change in domestic supply after opening to trade in the face of a potential production loss through the introduction of some disease can be represented rather straightforwardly. Call $\lambda$ the probability of losing the production following the appearance of the externality. Assuming risk-neutral domestic producers, the maximization of individual profits involves choosing output such that $\bar{\pi}_{O j}=p(1-\lambda) q_{O j}-1 / 2 c_{O} q_{O j}^{2}$ is maximized. $\bar{\pi}_{O j}$ is the expected profit before the realization of the loss, since the output decision is taken before the likely realization of the loss. Solving the individual maximization problem and summing over producers the total domestic supply obtained is: 
$\bar{S}_{O}(p)=\sum_{j=1}^{m} \bar{q}_{O j}=m(1-\lambda) p / c_{O}$. The higher $\lambda$, the greater is the pivotal shift of the inverse supply $\bar{S}_{O}$ to the vertical axis in Figure $4 .{ }^{12}$

Under free trade, the expected equilibrium price is $p^{G}$ and the total expected domestic welfare is given by area $0 \gamma G a$. The welfare comparison between autarky and free trade consists in comparing areas $0 \gamma \mu$ and $\mu G A$ (recall from above that welfare is $O A a$ under autarky). The welfare effect is ambiguous a priori. If $\mu G A$ is larger than $0 \gamma \mu$ the domestic welfare increases under free trade compared to the situation with a policy that impedes foreign imports. This case corresponds to a situation with a small probability $\lambda$ of losing production following trade liberalization.

Figure 4. Production externality, free trade

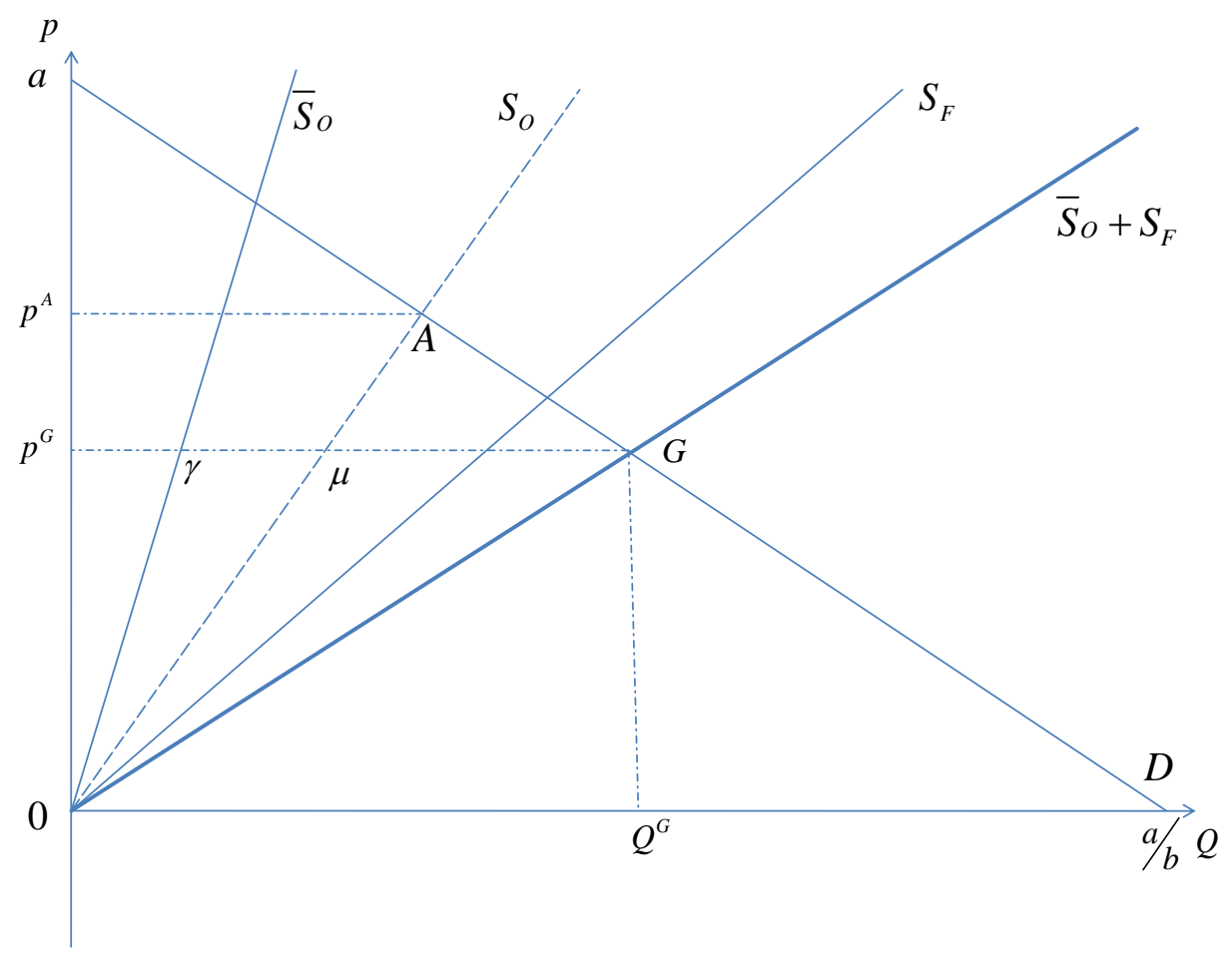

Note that a dynamic approach can be introduced by taking into account timevarying probabilities. Flows over several periods can be taken into account with a discount factor applied to welfare measures presented in Figure 4. Further sophistication can be added but ultimately the likelihood of the externality increases with trade.

12. Note that one extension of the framework could consider a case where the foreign supply $S_{F}$ is affected by some externalities. 


\subsection{Global-commons externality}

In the context of global-commons externalities two cases can be distinguished. As will become clear, the market consumption decisions and the public bad are separable in both cases.

In a first and simple case, consumers suffer a welfare loss from the externality, independent of their consumption decision. For example, biodiversity is being undermined even if they do not contribute to this failure with their consumption. The loss from this non-rival externality is separable from the utility derived from consumption and does not influence the demand for a good. Although this may seem counter-intuitive, this situation is conceptually equivalent to the situation where the "concerned" consumers do not factor the additional negative characteristic into their demand (with $I=0$ in equation 1). The concept is similar to the analysis of consumer-based externalities, with one important difference: concerned consumers cannot fully internalize the externality through their individual consumption decisions. The externality should be accounted for in the welfare calculations, but does not feedback in the demand.

In Figure 5 free trade leads to an equilibrium price $p^{E}$ that equalizes demand and total (domestic plus foreign) supply. Because their atomistic consumption decision does nothing to abate the global externality, it does not impact the demand of concerned consumers when the market opens to foreign producers (in equation (2) the demand is $\left.p_{2}(Q, 0)\right)$. However, the externality should be accounted for in the welfare calculations, but exactly how the externality should be measured is not entirely clear. One approach is to take the amounts imported and consumed and to multiply this by the unit damage that concerned consumers attach to the global commons externality. This would yield the value of the externality as $r_{2}(1-\beta) Q^{E}=r_{2} Q_{2}^{E}$, where $Q_{2}^{E}$ is the consumption by the proportion $(1-\beta)$ of concerned consumers at the price $p^{E}$. This approach to accounting for global commons externalities as separable from consumption follows (Foster and Just, 1989 and Teisl et al., 2001). Adding the usual consumer surplus (area $p^{E} E a$ ) and producer surplus (area $O z p^{E}$ ) to the externality (area $0 r_{2} t Q_{2}^{E}$ ) yields overall domestic welfare under free trade as the area $0 z P^{E}+P^{E} E a-0 r_{2} t Q_{2}^{E}$.

Imposing an import ban eliminates foreign supply from the domestic market. The welfare comparison between autarky and free trade consists in comparing areas $0 r_{2} t Q_{2}^{E}$ and $z E A$ (the combined consumer and producer surplus under autarky yields total welfare as area OAa ). The area $z E A$ represents a welfare gain under free trade, while area $0 r_{2} t Q_{2}^{E}$ is the loss value that concerned consumers attach to negative global externality. Welfare under a prohibitive import ban is increased if the per-unit damage $r_{2}$ is relatively large so as to outweigh the benefits of lower domestic prices under a free trade regime.

The above analysis has taken as the basis for valuation the imported and consumed quantities of the good that is linked to the global commons externality. Alternatively, if the externality comes from the production side (as in the case of rainforest destruction) its size could also be measured based on the total quantity of foreign production, and not just on the amount imported and consumed domestically. This approach would yield a value of the externality that depends on total foreign production, and would increase with the total amount of production (the more rainforest is destroyed, the higher the value attached to the remaining rainforest). Although this alternative measurement of the externality 
does not lend itself easily to graphic exposition in Figure 5, its principle is not fundamentally different from the welfare accounting based on imports. As before, consumer and producer surpluses will have to be amended by a valuation of the global commons externality to obtain a measure of total welfare under alternative policy settings.

Figure 5. Global commons externality

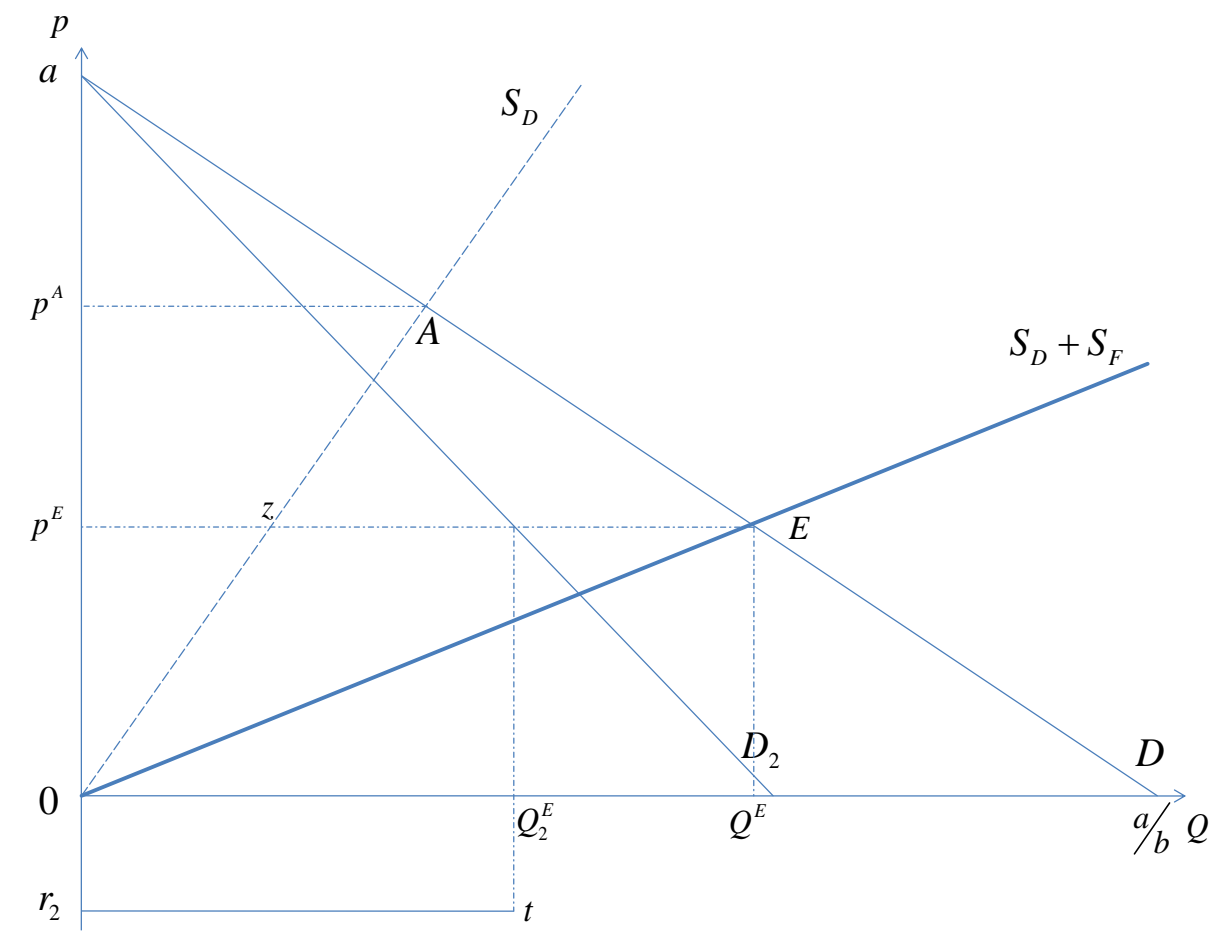

A second case, not fully developed here, includes global commons when concerned consumers reduce their consumption to feel better, although their individual impact on the non-rival externality is small. In this latter case, the externality feeds back into demand decisions of concerned consumers but the externality can typically not be fully internalized. The consumption decrease is too marginal to induce suppliers, whose supply causes the adverse effect on global commons, to change their behaviour. Concerned consumers will decrease the consumption of goods linked to the global commons problem to feel better. They may switch to a sustainable good with an eco-label if such good is available. This latter situation corresponds to the case of the concerned consumers being informed $(I=1)$ in equation (2), even though the consumers do not fully internalize the externality as the global commons tragedy continues to develop. This second case combines elements of the case where concerned consumers adjust their own consumption because of the negative externality or they would switch to a "sustainable" substitute fulfilling the eco-label standards. Nevertheless, the externality is not fully internalized because other unconcerned consumers purchase the regular good which contributes to the global commons problem. The externality can be reduced but not eliminated unless all consumers globally consume the eco-labelled good. 


\subsection{Extensions}

\section{A non-prohibitive standard}

In the previous exposition of the cost-benefit framework the standard was taken to be prohibitive, leading to an effective import ban. A more realistic approach should consider a standard impacting both domestic supply and foreign supply. Such a standard will increase production costs and it will reduce the impact of the specific characteristic that the concerned consumers want to avoid. To introduce a non-prohibitive standard consumers' utility and producers profit are re-formulated as follows:

$$
\begin{aligned}
& U_{i}\left(q_{i}, w_{i}\right)=a q_{i}-\bar{b} q_{i}^{2} / 2-I \times(1-\rho) \times r_{i} q_{i}+w_{i}, \\
& \pi_{O j}=p q_{O j}-1 / 2 c_{O} q_{O j}^{2}-k_{O}(\rho) q_{O j}-K_{O}(\rho), \text { and } \\
& \pi_{F j}=p q_{F j}-1 / 2 c_{F} q_{F j}^{2}-k_{F}(\rho) q_{F j}-K_{F}(\rho) .
\end{aligned}
$$

Firms bear an effort $\rho$, scaled such that $0 \leq \rho \leq 1$, that reduces the damage $r_{i} q_{i}$ for consumers. With this specification, the effort increases domestic and foreign firm's marginal costs $k_{O}(\rho)$ and $k_{F}(\rho)$, along with sunk costs $K_{O}(\rho)$ and $K_{F}(\rho)$. Firms now face two interdependent decisions: the level of effort to comply with a standard and the level of production. The optimal choice will depend on market structure and on the kind of strategic interaction between firms. In equilibrium, the marginal costs of effort are passed on to consumers through the price. When firms incur compliance costs that are sunk, these costs are not passed on directly to consumers in the price.

For the cost-benefit assessment of a standard, its level may be taken as given. Alternatively, an optimal level of the standard can be determined by letting domestic, or international regulators take a welfare measure into account (Fisher and Serra, 2000). For example, a domestic regulator may select a standard that maximizes domestic welfare (defined as the sum of the domestic agents' surplus). This level may hurt foreign producers if it imposes prohibitive costs, $k_{F}(\rho)$ and $K_{F}(\rho)$. On the other hand, an international regulator would choose a standard that maximizes global welfare. One can also consider a combination of several instruments as a standard and a label (see Marette, 2007 and 2008).

\section{Industrial organization considerations, firm entry and exit}

Initially it was assumed that sunk costs $K_{O}$ and $K_{F}$ were equal to zero. This assumption implies that firm exit can be ignored. However, if sunk costs are non-zero, profits may be become negative, leading to exit by some firms. If sunk cost depends on the compliance efforts a standard may lead to exit by some firms. Some foreign firms may exit the market until the other firms offering products break even. This issue is particularly sensitive if the fixed compliance costs are higher for foreign suppliers than for domestic firms. Rau and van Tongeren (2007) show the impact of fixed and variable compliance costs on market structure, in a context with complying and non-complying Polish suppliers to EU safety standards for meat.

In his path-breaking analysis Sutton (1991) shows that demand shifting activities, such as a standard, may also be used by a firm or a regulator against rivals, in particular 
foreign firms. A key insight from this work is that concentration increases as market size increases, for example through trade liberalization, if the demand shifting attribute is produced at an endogenous set-up cost, as outlined above. Although Sutton's analysis looked into R\&D and marketing, his insights pertain equally to food safety or food quality standards. By selecting a relatively high level of quality and safety standard that involves a significant set-up cost, potential foreign competitors can be driven out of the domestic market. Since incumbents do not pass the sunk cost to consumers they can choose an aggressive pricing strategy, thus eliminating potential rivals. As a result, concentration at the producer level increases and product variety could decrease. This latter mechanism is also found in trade models with heterogeneous firms. Chaney (2005) and Rau and van Tongeren (2008) show that higher fixed cost of exporting lead to shrinking extensive trade margin (less varieties) through exit of less productive exporters. In contrast, rising variable trade cost lead to a shrinking extensive margin as well as a shrinking intensive trade margin (less exports by all incumbent firms).

\section{Supply chain}

The framework developed here focused on the end-product, ignoring the upstream and downstream effects of NTMs. These could be included by modelling the successive processing stages. In particular, a market for input factors could also be introduced, which would make variable costs $c_{O}$ and $c_{F}$ endogenous. This would allow the relative impact of a standard imposed on the input versus a standard imposed on the output to be measured.

The introduction of vertical relationships between suppliers in the supply chain raises the issue of private standards. Reardon et al. (2003), Fulponi (2006), OECD (2006 a,b) and $\operatorname{OECD}(2008$ a,b), underscore the rising importance of private standards. The development of private standards raises important issues regarding the future direction of food safety and quality regulation. Private standards represent a shift in responsibility from public agencies to private industry. This raises questions over the degree to which regulation is driven by private rather than public considerations. The recent growth of private regulation also increases the range of standards with which firms must comply. This could significantly increase the total regulatory burden on the food system and consumers.

\section{Foreign consumers and foreign governments}

A comprehensive analysis should take foreign consumers and foreign governments into account, perhaps imposing their own policies. Since regulations tend to differ between countries, especially if they are at different levels of development, this raises the issue of mutual recognition or harmonization.

\section{Border inspections and other non-tariff border measures}

Inspections at the border or other non-tariff border measures such as single port of entry lead to increased variable trade costs. Conceptually these can easily be incorporated by introducing a tariff-equivalent of such measures that increases the foreign supply price paid by domestic consumers. Hummels (2001) develops a method to empirically estimate the tariff equivalent of time delays at the border. 


\section{Pre-shipment inspection}

Instead of inspecting goods once they arrive in the port of destination, compliance may be checked at the point of departure (perhaps even at the production facilities). For the assessment of the effects of those measures, it should be taken into account who bears the pre-shipment inspection costs. If it is the country of destination, it should be accounted as a cost in the importing country. However, if costs have to be borne by the exporter, it obviously increases the cost of exporting. Inspection costs might also be split between the two countries. Regardless of the question who pays the inspections costs, their incidence operates like a tax on imports.

\section{Recent advances in measuring valuation of market failures and global commons}

This section discusses recent advances in empirically measuring the valuation that consumers attach to product characteristics. Arguably, this is the most critical part of the analysis, as consumer's willingness to pay for (or avoid) certain product characteristics largely determines the welfare assessment. The crucial challenge is the assessment of consumers' valuation when a market for the good does not exist. This is typically the case when dealing with externalities and information asymmetries, but also when current trade policies exclude imports. It is beyond the scope of this report to provide an exhaustive overview of valuation methods, and the treatment here focuses on recent developments, including experimental economics. An excellent overview of theories and methods is provided in OECD (2006c). As this publication does not discuss experimental methods, this report elaborates somewhat on this approach which is increasingly being used and is of particular relevance to issues treated in this report.

\subsection{Consumer valuation of failures}

Numerous methods exist for eliciting people's values for both market and nonmarket goods (such as externalities or environmental goods). Many of them are potentially tailored to the analysis of NTMs, since they capture heterogeneity in consumers' preferences. The quality of a cost-benefit analysis critically depends on these measures. Two types of non-market valuation methods can be used, namely the QALYs approach, discussed in Section 6 above, and the WTP approach.

QALYs methodologies may be incorporated into the cost-benefit framework proposed here, in particular for damage for which consumers are not aware (Figure 3). As discussed in Section 6, a drawback of this approach is its inability to reflect responses of consumers in demand. In other words, the costs estimated through QALYs methods have no equivalent in terms of demand adjustments linked to reactions of consumers, as the adjustments presented in the figures above.

In contrast, methods based on estimates of WTP allow economists to assess consumers' reaction. These methods make it possible to include quality-related aspects that cannot be translated into identifiable short-term illness.

The preventive expenditure method seeks to measure agents' willingness to pay by observing the efforts made to avoid illness. With this method, a money evaluation of the disutility of being ill is added to the estimated cost of illness, together with an estimate of the preventive expenditure that an individual is willing to commit according to a given pathogen level (Harrington and Portney, 1987). 
Contingent valuation methods involve asking individuals directly about their willingness to pay in order to reduce the risk of an illness, or more generally to obtain higher quality in a good. Choice experiments indirectly determine WTP by econometric estimation based on various choices made by consumers. Experimental economics (including lab, field or natural experiments) brings a group of individuals into a situation, where their real behaviour is simulated (in the lab) or influenced (in the field) to reveal their willingness to pay for particular qualities (see Lusk and Shogren, 2007a, for an exhaustive presentation). One advantage of the experimental method is the precise control of the information revealed to consumers, including a measure of their initial knowledge via ex ante and ex post questionnaires. The numerical example presented below uses WTP measures derived from laboratory choice experiments. Note that a price premium for differentiated products that are already sold on a given market may be estimated by some econometric method based on hedonic prices. This is for instance the case for the eco-label valuation (see Nimon and Beghin, 1999, and Teisl et al., 2002).

Before briefly detailing some of these WTP methods, it is particularly important to reflect on the robustness of these methods, in particular respondents' incentives to overor underestimate their WTP (see Shogren, 2006). Different WTP methods have been compared in order to elicit biases (see a survey in Levitt and List, 2007). From a comparison with a field experiment, Blumenschein et al. (2008) showed that the hypothetical bias linked to contingent valuation can be removed by a certainty statement at the end of the questionnaire. List (2007) notes that field experiments, despite their limitations, may be useful bridges between lab experiments and real situations. While still being relatively nascent, the use of experimental economics methods can be seen as a major breakthrough to obtain more robust estimates of consumer WTP. Several papers have directly compared the results of lab experiments with other experiments (including field experiments in stores) or market data from supermarkets (eliciting a demand via econometric estimations). Among them, Shogren et al. (1999) showed that lab evaluations and market behaviour coincide at high price valuations, supposedly selecting the truly interested consumers. Lusk and Fox (2003) and Marette et al. (2008c) have shown that field valuations were close to but exceeded laboratory valuations. Chang et al. (2008) showed that for ground beef and wheat flour the results from lab experiments, where participants have to make real pecuniary commitments, outperformed the contingent-valuation approaches experiment in predicting retail sales. Despite their limitations, experimental results can be considered as a good approximation of consumers' or citizens' reactions, once some biases have been overcome. A main advantage of this method over other approaches is that it allows choice situations to be controlled more precisely, and hence allows in principle for transferring the results into other contexts.

Experimental methods have been widely used recently in many areas linked to food safety or food preferences for some characteristics such as GMOs, organic products, hormone treated beef, the value of biodiversity etc. (See Table 1.1 in Lusk and Shogren (2007b) with its 113 recent references). For issues like food safety, experiments reveal preferences for food safety (Hayes et al., 1995 for the US; and Rozan et al., 2004 for France).

The experiments about controversial goods, such as irradiated food or growth hormones such as rBST, are particularly tailored to analyze trade bans (as presented in Figure 1). They can capture heterogeneous preferences across countries and they provide experimental data when a foreign product is not available on the domestic market. Among the recent proliferation of studies or experiments on GMOs (see Costa-Font et al., 
2008 for a complete survey), several relate to the different regulatory environments in Europe and the US regarding GMOs. Noussair et al. (2002) show that a majority of French consumers is indifferent to GMOs, in comparison with non-GMOs, a view that contradicts the current regulatory practice. Huffman et al. (2003, 2007) show the sensitivity of WTP to the source of information (NGOs, Multinationals or public health authorities). Lusk et al. (2003) and Lusk et al. (2006b) directly compared WTP between the US and some European countries and show a larger level of reluctance to accept GMOs among European consumers compared to the US consumers. These results have been used to assess welfare effects of identity preservation between GMOs and nonGMOs (as for instance A. Sobolevsky, G. Moschini and H. Lapan, 2005).

The ban on hormone-treated beef in Europe inspired a specific experiment. Alfnes and Rickertsen (2003) show that most of the participants in Norway preferred domestic to imported beef. Hormone-treated beef received the lowest mean bid, but $28 \%$ of the participants were indifferent or preferred U.S. hormone-treated to U.S. hormone-free beef. Note that this type of experimental result justifies the simplifying partitioning of consumers into only two groups: concerned ones and indifferent ones.

Lagerkvist, Carlsson and Viske (2006), via a choice experiment, and Napolitano et al. (2008), via a lab experiment, measure WTP for animal welfare (including the use of hormones). Some experiments study the effect of the COOL (the country-of-origin-labels mentioning the geographic origin of products) program in the US (see Lusk et al., 2006a). Some studies elicit the WTP for biodiversity (Stoneham et al. 2003), even if the main technique used for this topic is contingent valuation.

By directly revealing willingness to pay, the experimental method makes it possible to obtain a monetary estimate of all the benefits arising from a given policy measure impacting trade. Note that almost all papers in lab experiments elicit WTP but do not integrate them into welfare analysis. By estimating the value of information, Rousu et al. $(2004,2007)$ come close to welfare measurement but without any link to a calibrated model.

\subsection{The valuation of producer-based externalities}

There is a large scientific literature estimating the impact of various pests and pathogens on agriculture (CABI Compendium, numerous articles in Weed Science, The Agronomy Journal, Weed Technology, among many other journals). The CABI Compendium series draws on available scientific information worldwide and includes a wealth of information on yield loss for a multitude of pathogens and pests on various crops, forest, livestock, and aquaculture. The Compendium series scan the last 40 years of scientific literature.

The most recent and visible reviews of the costs associated with invasive species are Pimentel et al. (2000) and Pimentel et al. (2005). Using a large survey of the ecological and agronomic literature, these two articles provide agricultural and environmental costs for an extensive list of invasive species. The uncertainty surrounding the latter estimates is huge but they nevertheless provide point estimates for yield losses or other shifts in the production function or in cost induced by these invasive species. The work by Pimentel et al. is a useful source to parameterize both losses in production and those associated with global common issues, such as loss of biodiversity, extension of endangered species and others. 
Progress has been considerable recently in integrating epidemiological models into economic analysis. Pendell et al. (2007) provide such an analysis for the US Midwest to analyze a hypothetical outbreak and spread of Foot and Mouth Disease. Several papers look at optimum quarantine policies (surveillance, tests, monitoring) in open or regional economies integrating sophisticated and realistic modelling of infestation dynamics and their spatial dimension (Adamson and Cook, 2007; Bicknell et al., 1999; Cook, 2007; Kompas and Che, 2003 and Kompas et al., 2004). These analyses rely on stochastic dynamic control, numerical methods, and sometimes spatial models, to quantify the diffusion and establishment of invasions and compute optimum quarantine intervention levels based on cost/benefit criteria. Results from these analyses can provide some range of values for simpler models integrating externalities as simpler supply shifts.

A large economic literature exists on weed infestation and the cost of managing them (e.g. Eisworth and van Kooten, 2002; Taylor and Burt, 1984; Jones and Medd, 2000; see also references in Pimentel et al., 2005). For example, Eiswerth and van Kooten (2002) analyze the supply impact of weed infestation on yield loss and cost of production on hay pastures for a non-indigenous weed, the yellow starthistle, and considering five management alternatives. This type of analysis provides sufficient information to assess yield loss if nothing is done and the cost of mitigating the invasion. These are the shifters needed to operationalize the cost-benefit framework. There is also an extensive interdisciplinary literature on yield losses induced by multiple invasive weeds and other pests, see for example Swinton et al. (1994) among many others.

Trade as a vector for entry of invasive species has been also studied. Costello et al. (2007), and others look at the introduction of various invasive species in US harbours over time and the associated welfare cost. Levine and d'Antonio (2003) analyze the statistical relationship between trade and invasive species for a large set of pests.

In regard to genetically modified products, Wolfenbarger and Phifer (2000), and Qaim and Matuschke (2005) review the available scientific evidence on the cost and benefits of growing GMO crops instead of conventional ones, including yield effects, savings on pesticides, and larger ecological costs having to do with non depletable externalities similar to global commons valued by consumers. Piggott and Marra (2007) analyze the farm level costs and benefits associated with two types of refuge policy and spraying alternatives at the farm-level and for a large seed company, of policy for GMO cotton. Marra and Piggott (2006) analyze the non pecuniary benefits associated with various GMO crops relative to conventional ones.

\subsection{The valuation of global commons}

Trying to put a value on avoiding mismanagement of resources that are seen to belong to the global community is perhaps the most controversial of the cases discussed in this report. While countries agree in principle on issues such as the importance of remedial action to avoid climate change or to prevent loss of biodiversity, they disagree in practice when it comes to developing mechanisms that enforce more ecologically sustainable behaviour. Differences in valuation of the global commons and unequal distribution of costs of remedial action are at the root of difficult multilateral negotiations on these topics.

In the context of global commons, economists typically divide the total economic value into "use values" (value derived from using a resource) and "non-use values." The latter can be distinguished into "existence values" (the sheer presence of a certain eco- 
system is valued positively) and "option values" (although the resource is not used now, there is value to having this option to use it later).

Numerous studies exist today that provide some estimates on each of those components, see the references in the digital library of the commons maintained by Indiana University (http://dlc.dlib.indiana.edu/). The most far-reaching, but not uncontroversial, attempt to value global ecosystems services is documented in Costanza et al (1997). This study estimates direct and indirect use values of 17 ecosystem services, such as gas regulation, water supply and nutrient cycling. The study is based on previously published data, supplemented with some additional calculations.

If a certain "commodisation" of the global commons externality can be arranged by creating a real market, consumer valuation can be directly observed, and it is not necessary to resort to the non-market valuation methods discussed previously. The price premium that consumers in importing countries are willing to pay for sustainably produced products over non-sustainable ones directly reveals information about their valuation of the global commons in question.

A valuation study addressing global commons issues that is conceptually very close to the framework proposed in this report is provided by Larson (2003). He shows how labelling of shade-grown coffee could contribute to internalizing positive environmental externalities into consumer demand. Positive effects on tree flora and bird fauna are attributed to coffee grown under shaded, small scale and lower yield conditions.

Large scale and government-backed attempts exist in sustainability labelling schemes for tropical timbers and in marine fisheries. The International Tropical Timber Organisation finds in a recent study (ITTO, 2008) that buyers in importing countries have generally not been willing to pay a large premium for certified products. Observed price premiums can be as low as $2 \%$ for UK imports of MTCC-certified meranti sawnwood from Asia, to reach 10-30\% for certified tropical timber used in marine construction in Denmark. However, no price premiums have been reported in the Japanese market. Such variation in price premiums can partly be explained by differences across importing countries in consumer valuation of tropical forest. Price premiums differences across exporting countries can partly be explained by uncertainty about the truthfulness of the label which leads to varying price premiums, especially for imports from Africa.

If a price premium is possible, the risk of free-riding also emerges. Producers have an incentive to save on the additional cost of more sustainable resource use, including the cost of certification and identity preservation, while still labelling their product as being of the sustainable variety. If the monitoring of the labelling is imperfect, and consumers learn about this loophole, the value of information carried by the label and the certification scheme will be undermined. This can prompt importing countries to resort to alternative NTMs. Norway, for example, has decided in 2007 to ban all tropical timber from publicly procured construction, regardless of the label.

\section{Towards implementation of the framework}

This section explains how the framework proposed in section 6 can be made operational for actual policy analysis. The section goes through the usual steps involved in implementation of a model, from specifying functional forms to finding estimates of important parameters of the specified model, and various data types required to calibrate the model and their sources. 


\subsection{Parameterization}

Even if a product with a specific characteristic is not available on the domestic market, and hence demand cannot be observed, supply and demand functions can be calibrated. The WTP for the specific characteristic can be obtained from contingent valuation studies or experimental results, as discussed above. Under autarky or under a prohibitive policy precluding imports of foreign products, parameters of the linear demand and supply functions can be calibrated to domestic market prices and quantities.

Without the introduction of the foreign product, the demand and supply equations on the domestic market are represented by linear approximations with the corresponding elasticity at the point of approximation. From equation (2), the overall demand without information (with $I=0$ ) is defined by $Q(p)=(a-p) / b$. With the observed quantity $\hat{Q}$ sold over a period, the average price $\hat{p}$ observed over the period, and the direct price elasticity $\hat{\varepsilon}(=(d Q / d P)(P / Q))$ obtained from econometric estimates, the calibration leads to estimated values for the demand equal to $1 / \tilde{b}=-\hat{\varepsilon} \hat{Q} / \hat{p}, \tilde{a}=\tilde{b} \hat{Q}+\hat{p}$. Section 8.2 below mentions several elasticity databases that are publicly available to draw from.

WTP estimates coming from experiments or contingent valuation have to be integrated in the calibrated demand. A pre-condition is of course that the sample used in the experiments is representative of the general population analyzed in the investigation. ${ }^{13}$ From experimental results, the proportions of indifferent and concerned participants can be identified.

Results from choice experiments can subsequently be integrated into the calibrated demand function for the proportion of consumers interested in or reluctant to consume a specific characteristic in a way consistent with the framework defined by equation (1) and (2) in subsection 6.1. ${ }^{14}$ The revelation of information in the lab allows participants to know the characteristic provided by the foreign product introduced under free trade (with or without a mandatory label). This procedure allows the WTP for the specific characteristic to be isolated econometrically. Of course, the changes in WTP from the experiment can only be used reliably in the calibrated model if the impact of information is statistically significant.

Under free trade, the undesirable characteristic of the foreign good is unpalatable for concerned consumers. It causes a parallel inward shift of the demand curve at the initial equilibrium price which is in keeping with the model of Polinsky and Rogerson (1983) and Lichtenberg et al. (1998). The relative variations of WTP observed in the experiment focusing on the additional characteristic serve to determine the demand shift (see Marette et al., 2008a for details).

The demand variation based on the lab experiment is measured in a vertical demand "decreasing" shift and leads to $D_{2}$ in Figure 2 with $\delta=\left[E\left(W T P^{h h}\right)-E\left(W T P^{h}\right)\right] / E\left(W T P^{h}\right)$, where $E($.$) denotes the expected value of the$ WTP for subjects of the experiment who significantly change their WTP after the

13. This eliminates experimental studies made with students on campus.

14. Note that this group could also be divided into several subgroups according to the importance of the WTP shifts. 
revelation of the information about the characteristic of the imported product (namely $W T P^{h h} \neq W T P^{h}$ ), and where $h$ denotes the situation before the information was revealed and $h h$ denotes the situation after. The relative change $\delta$ isolates the relative WTP for the additional characteristic independently from the initial endowment or the initial value of the product offered during the experiment. With the model calibrated for an initial price $p^{A}$ and integrated in the cost benefit analysis the value of the shift is $r_{2}=-\delta p^{A}$. This is to be incorporated into equation (2), with a decreasing demand shift for $\delta<0$ and positive demand shift for $\delta>0$. This value measures the shift of the demand calibrated at a price $p^{A}$. Note that the welfare computed with unaware consumers can also be estimated with this measure (see Marette et al. (2008b) for details).

\subsection{Data sources}

\section{WTP measures}

As explained in section 7, WTP measures linked to contingent valuation or lab experiments can be directly estimated or alternatively they can be found via meta-analysis of published results. Remaining parameters can often be obtained from outside sources. When using secondary data, it is important to make allowance for the specific situational context and country context in which these estimates are made. WTP estimates obtained in one specific country and in one specific context may not be directly transferable to other situations, and adjustments may be necessary to take such differences into account.

\section{Elasticities}

Demand and supply price and income elasticities are available from two databases extensively used for partial equilibrium modelling: FAPRI (http://www.fapri.iastate.edu/tools/elasticity.aspx) and USDA-ERS (http://www.ers.usda.gov/Data/InternationalFoodDemand/. The database underlying the OECD/FAO Agkink-Cosimo model also provides a multitude of elasticity estimates OECD (2007b) and http://www.agrioutlook.org/pages/0,2987,en_36774715_36775671_1_1_1_1_1,00.html. Recent estimates of import demand elasticities are provided by Kee et al. (2008) who estimate such elasticities for goods disaggregated at the HS-6-digit level for a large set of countries.

\section{Data on policies and trade frictions}

Two databases have hitherto been central to the analysis of TBTs and SPS regulations. First, WTO notifications of some NTM measures are collected and processed by the United Nations Conference on Trade and Development (UNCTAD) in the TRAINS database. UNCTAD complements the notifications using national sources and categorizes the various measures into a policy classification of its own as follows: paratariff measures, price control measures, finance measures, automatic licensing measures, quantity control measures, monopolistic measures, and technical measures. These categories are further disaggregated into finer policy types (see http://r0.unctad.org/trains new/tcm link.shtm). TRAINS is available at a cost through the WITS system maintained by the World Bank (http://wits.worldbank.org/witsweb/). WITS makes these data available at the HS-6 commodity level and allows several official 
motives of the policies (health protection, environmental protection, etc) to be identified. This database was recently used by Disdier et al. (2008); Fontagné et al. (2005); and Henry de Frahan and Vancauteren (2006), among others. A drawback of these datasets arises from uneven reporting by countries and heterogeneous coverage of measures across countries and commodities. It may say more about reporting behaviour than regulations. For a discussion of this database see OECD (2008c).

The second important database recently used is Perinorm (www.perinorm.com), a bibliographic database sponsored by the British, German, and French industrial norm agencies (BSI, DIN and AFNOR). It provides information on public standards, which are voluntary, and technical regulations, which are mandatory. Hence, both mandatory and voluntary standards are covered. The database includes national, European and international standards from 23 countries, and provides a total of more than 1,100,000 records on standards from Australia, EU countries, Japan, and the USA. This database was used by Moenius (1999) and (2006) and by Czubala, et al. (2007). These authors ingeniously use the data to identify bilaterally shared standards from non-shared ones (Moenius) and international standards from non-harmonized ones (Czubala et al., 2007). Czubala et al. rely on Perinorm in combination with the online catalogue of the European Committee for Standardization to create an original database of EU product standards applied to textiles and clothing. These data distinguish between "harmonized" standards that are equivalent to ISO standards and those that are not. The inclusion of voluntary standards in Perinorm is an advantage compared to the notifications data developed by UNCTAD representing mandatory TBTs, but the country coverage is much more limited.

The newly created WTO SPS Information Management System (SPSIMS) (http://spsims.wto.org/) provides new and easier access to SPS notifications to the WTO as well as to official trade concerns communicated by Members to the SPS Committee of the WTO. SPSIMS essentially provides online access to textual information. The public version of the system provides SPS information, concerns, and notifications according to their specific needs using searches based on various criteria (geographic groupings, product codes, comment periods, and keywords). The SPS section of the WTO website is a major source of information on mandatory standards and disputes. These SPS notification data are also available through the Inquit database (www.inquit.com). It offers convenient access to SPS measures from September 1999 to May 2007. WTO dispute data has been compiled and analyzed by and are available from Horn and Mavroidis (2006).

Information on international legal instruments relating to food safety is made publicly available through the International Portal on food safety, animal and plant health (IPFSAPH) http://www.ipfsaph.org/). IPFSAPH is a joint undertaking between a number of SPS-recognized standard-setting organizations and international agencies. It was developed by FAO in association with Codex Alimentarius, the IPPC Secretariat and OIE. The database contains binding international legal instruments relating to food safety: international instruments (those developed by standard setting bodies, such as OIE, Codex Alimentarius), regional instruments (mainly European Union regulations), soft law instruments (such as OECD safety considerations for biotechnology 1992, and the FAO Code of conduct for responsible fisheries). The portal provides search facilities by commodity, by country and by cross-sectoral issues (such as human health impact).

The World Bank has also a database developed by Wilson and associates on trade facilitation using survey information from the World Economic Forum. In addition, the World Bank Technical Barriers to Trade Survey (Wilson and Otsuki, 2004b) 
(http://www1.worldbank.org/wbiep/st-db/) is the first attempt to globally investigate the impacts of technical requirements with surveys. They collect information from agricultural, manufacturing, and trade firms in various emerging market countries regarding technical barriers encountered in export markets, which impact their ability to successfully export. The data collected cover 689 firms in over 20 industries in 17 developing countries.

\section{An illustration: labelling of fish}

The following example illustrates the application of the cost-benefit framework for NTMs. It assesses the impact of mandatory labelling in the case of fish consumption in France and is based on Marette et al. (2008a). The illustration evaluates the impact of a label providing health information affecting consumer choice between a relatively "risky" type of fish (i.e. tuna) and a type of fish that is not only "less risky" but in addition offers health benefits (i.e. sardine). From a health policy perspective, a shift of consumption towards sardines is desirable because the latter contains more of the healthy omega-3 fatty acids and less of the unhealthy methylmercury than tuna does. However, policies that induce substitution away from tuna have international trade implications, as most canned tuna (95\%) and canned sardines (99\%) consumed in France is imported. In particular, foreign producers of tuna would face a declining demand after the revelation of information about risk (as in Figure 3). This could have significant impact on tunaexporting countries in the developing world, such as Ivory Coast, and the Seychelles (Ofimer, 2007). This example corresponds to a welfare evaluation that is very close to the case comparing Figure 2 and Figure 3 above. The possibility of a prohibitive standard, amounting to a ban on tuna imports, is not considered here, but would be conceptually close to the comparison of Figure 1 and Figure 2 above. The price impact of a prohibitive ban would likely be substantial.

To obtain consumer's valuation of the health attributes and to obtain an assessment of the value of product information linked to a mandatory label, a laboratory choice experiment was conducted. Subjects invited to participate were French women of childbearing age, since fish is particularly important during pregnancy. Following the methodology described in subsection 9.1, the results of the experiment are calibrated with market data and elasticity estimates to determine the value of the information. Compared to the framework outlined in this report, an additional factor is the presence of two goods (tuna and sardines) that are substitutes in consumption.

Parameters of the model are initially calibrated such as to replicate prices and quantities in France for the year 2002 (Table 2), the most recent complete year when the analysis was undertaken. For the supply side, a linear supply function is calibrated to elasticity estimates that are found in the literature. The calibration of linear demand function parameters uses own-price and cross-price elasticity estimates for both tuna and sardines. Three different demands are calibrated for the initial situation without information on product attributes: 1) A group of consumers who purchase both tuna and sardines; 2) a group of consumers who only purchase tuna; and 3) consumers only purchasing sardines. The aggregation of demands of different subgroups leads to the overall demand.

The initial demand allows welfare to be computed in the absence of health information. The welfare impact of information is obtained using the results from the lab experiment to update demand after the health information has been revealed. 
It is assumed that only the demands of consumers consuming both types of fish are modified by health information provided to them. ${ }^{15}$ From the choice behaviours in the experimental setting the response to product information can be observed. From the experiment and from the definition of $\delta$ in subsection 9.1, the average increase in the relative sardine WTP is $\bar{\delta}_{\text {sardine }}=0.79$ after the revelation of information, which leads to an increasing demand shift (see Marette et al., 2008a). The average change in the relative

tuna WTP is $\bar{\delta}_{\text {tuna }}=-0.21$ after the revelation of information, which leads to a decreasing demand shift. These values from the experiment sample are extrapolated to the corresponding French population to calibrate the shifts in demands for tuna and sardines. In order to single out the subgroup of the consumers being "at risk", or "concerned", from those that are "indifferent" (not concerned by the health message of this experiment), the analysis assumes that only households with women of childbearing age and/or with young children under age 14 are relevant (recall that only women of childbearing age participated in the experiment since this group is targeted by food safety authorities). This distinction is made on the basis of medical evidence that clearly identifies this group as being at greater risk. The group of households "at risk" represents 50.5\% of French consumers. The rest of the population is considered as completely indifferent with $\delta_{\text {sardine }}=0$ and $\delta_{\text {tuna }}=0$, which is a restrictive assumption.

Table 2. Demand Specification for canned tuna and canned sardines in France

\begin{tabular}{|c|c|c|c|}
\hline Variable & Description & Values & \\
\hline \multirow[t]{3}{*}{ Canned Tuna } & Overall consumption in France in 2002 (in tons) & 63845 & \\
\hline & Average price in 2002 (in euros) & 6.1 & \\
\hline & Supply elasticity & 0.2 & \\
\hline \multirow[t]{3}{*}{ Canned Sardines } & Overall consumption in France in 2002 (in tons) & 11484 & \\
\hline & Average price in 2002 (in euros) & 8.2 & \\
\hline & Supply elasticity & 0.2 & \\
\hline Consumers & 1) purchasing both sardines and tuna & & \\
\hline \multicolumn{2}{|c|}{$\%$ of households consuming sardines and tuna ${ }^{3}$} & $65 \%$ & \\
\hline & Demand elasticities & Tuna & Sardines \\
\hline & Own-price & $-0.58^{*}$ & $-0.476^{*}$ \\
\hline & Cross-price & $-0.059^{*}$ & $0.144^{*}$ \\
\hline Consumers & 2) only purchasing tuna & & \\
\hline \multicolumn{2}{|c|}{$\%$ of households consuming only tuna } & $32.5 \%$ & \\
\hline & Own-price elasticity of demand & $-0.534^{*}$ & \\
\hline Consumers & 3) only purchasing sardines & & \\
\hline \multicolumn{2}{|c|}{$\%$ of households consuming only sardines } & $2.5 \%$ & \\
\hline & Own-price elasticity of demand & $-0.451^{*}$ & \\
\hline
\end{tabular}

Source: Marette et al. (2008a). For the estimation for the elasticity, * indicates significance at the 5\% level in the regression between the log of quantities and the log of prices.

15. An extension could allow for the additional possibility that consumers who only purchase tuna and consumers who only purchase sardines change their consumption but the experimental procedure based on the substitution between these products was not designed for this case. 
To measure different forms of information diffusion, a case where all the $50.5 \%$ of concerned households receive health information is distinguished from a case where only half of these concerned consumers are reached by this information. The change in profits for foreign producers of canned tuna and canned sardines can be singled out from the supply chain profits (canning industry and domestic retailers). The estimation of foreign producers' profits takes into account the share of imports relative to domestic consumption of canned fish (95\% for canned tuna and 99\% for canned sardines) and it takes into account the share of the canning industry in the total value added of the supply chain. Based on import prices and retail prices, the estimated share of the consumer price received by the tuna canning industry is $48 \%$ and the share of the consumer price received by the sardines canning industry is $37 \%$. The rest of the total value added goes to the French retailers. We now turn to the results.

Table 3. Economic effects of labels (information) to prices and different groups (in euros)

\begin{tabular}{|c|c|c|c|c|}
\hline & & Unit & $\begin{array}{l}\text { All concerned } \\
\text { consumers } \\
\text { receive } \\
\text { information } \\
(50.5 \% \text { of } \\
\text { population }) \\
\end{array}$ & $\begin{array}{c}\text { Half of the } \\
\text { concerned } \\
\text { consumers receive } \\
\text { information } \\
(25.25 \% \text { of } \\
\text { population) } \\
\end{array}$ \\
\hline \multicolumn{5}{|l|}{ Price variations } \\
\hline$\Delta p_{T}$ & Tuna absolute & Euros & -0.28 & -0.14 \\
\hline$\Delta p_{T} / \hat{p}_{t}$ & Tuna relative & $\%$ & $-4.6 \%$ & $-2.3 \%$ \\
\hline$\Delta p_{s}$ & Sardine absolute & Euros & 3.70 & 1.85 \\
\hline$\Delta p_{s} / \hat{p}_{s}$ & Sardine relative & $\%$ & $45.2 \%$ & $22.6 \%$ \\
\hline \multicolumn{5}{|c|}{ Surplus variation when prices vary } \\
\hline$\Delta \Pi_{T}$ & $\begin{array}{l}\text { Change of profits for the total } \\
\text { canned tuna supply chain }\end{array}$ & Euros & -21579855 & -10832098 \\
\hline$\Delta \Pi_{T}^{F}$ & $\begin{array}{l}\text { Change of profits of foreign } \\
\text { producers }\end{array}$ & Euros & -9977086 & -5008039 \\
\hline$\Delta \Pi_{S}$ & $\begin{array}{l}\text { Change of profits for the total } \\
\text { canned sardine-supply chain }\end{array}$ & Euros & 54931214 & 26503449 \\
\hline$\Delta \Pi_{S}^{F}$ & $\begin{array}{l}\text { Change of profits for foreign } \\
\text { producers }\end{array}$ & Euros & 20444841 & 9864315 \\
\hline$\Delta \Pi_{S}^{F}+\Delta \Pi_{T}^{F}$ & $\begin{array}{l}\text { Change of total foreign } \\
\text { producers profits }\end{array}$ & & 10467755 & 4856276 \\
\hline$\Delta C S_{1}$ & $\begin{array}{l}\text { Change of surplus non- } \\
\text { concerned consumers }\end{array}$ & Euros & -13830515 & -12576828 \\
\hline$\Delta C S_{2}$ & $\begin{array}{l}\text { Change of surplus concerned } \\
\text { consumers }\end{array}$ & Euros & 7609339 & 8403685 \\
\hline$\Delta W^{O}$ & Domestic welfare & & 16662428 & 6641931 \\
\hline$\Delta W$ & $\begin{array}{l}\text { Total welfare (domestic } \\
\text { welfare+ foreign profits) }\end{array}$ & Euros & 27130183 & 11498207 \\
\hline$\Delta W / W(\%)$ & Relative total welfare change & $\%$ & $2.8 \%$ & $1.2 \%$ \\
\hline
\end{tabular}

Source: Marette et al. (2008a) and authors' estimation for profits of foreign suppliers. 
Table 3 provides the economic impact of information on prices and surpluses of agents for the year 2002. The demand shifts imply a fall in the equilibrium price for tuna $\left(\Delta p_{T}<0\right)$ and an increase in the equilibrium price for sardine $\left(\Delta p_{S}>0\right)$. The price change for sardines is larger than the absolute value of the price change for tuna, because the demand-increasing shift for sardines is larger than the demand decreasing shift for tuna. Consequently, profits for tuna producers fall, while profits for sardine producers surge. Foreign tuna producers suffer from the revelation of information, but this loss is outweighed by the benefit to foreign sardine producers, since the change in total foreign profits is positive. Retailers who capture more than half of the value added in the supply chain (52\% of the consumer price for tuna and $63 \%$ of the consumer price for sardines) benefit from the revelation of information. Consumers in households at risk benefit from the information, as shown by the positive change of their consumer surplus. This group benefits from having the possibility to make better informed consumption decisions. The change in surplus of these concerned consumers is a little higher when half of the concerned consumers receive information compared to the full revelation to all concerned consumers (EUR 8.4 million compared to EUR 7.6 million ). Indeed, the benefit linked to additional information mainly comes from information about the omega 3 content of sardines. However, the large upward price effect for sardines partially cancels out these benefits linked to the revelation of information. Consumers not concerned by the information suffer from the subsequent change in market prices with a negative change in their consumer surplus. This loss comes from the large price increase for sardines that outweighs the positive impact of the small price decrease for tuna. As non-concerned consumers mainly consume tuna, the change in surplus of these non concerned consumers is of similar magnitude under both scenarios since the price variation of tuna is relatively low with a relatively inelastic demand. Table 3 shows a positive net welfare gain from informing households at risk despite some losses for tuna producers and for consumers not concerned by the revealed information.

Note that this analysis could be extended by considering other NTM instruments, such as a mercury standard imposed on tuna, and tax and subsidy instruments (Marette et al., 2008b). As underlined above, the results of this type of analysis depend on the configuration of parameters and on the quality of data used. To determine the robustness of the results and to underline its limits a thorough sensitivity analysis with alternative assumptions, ranges of parameter values and different scenarios can be employed. Showing whether a conclusion is robust under a range of plausible parameters can be more valuable than one single positive welfare estimate. This simple example illustrates the applicability, feasibility, and flexibility of the proposed framework.

\section{Concluding remarks}

This report opens the way toward a systematic analysis of economic costs and benefits of NTMs. The proposed methodology is operational for comparing alternative policy choices like standards, border inspections policy and labelling in an international context. The methodology contributes to a more comprehensive welfare analysis of NTMs than that offered by looking at trade affects alone.

Efficiency costs of NTMs are much less evident than the welfare losses associated with tariffs and quota. NTMs do not necessarily embody the economic inefficiencies that are associated with classical trade barriers, unless they discriminate between sources of supply, and they may be the least trade-restricting policies available in the face of market 
imperfections. It is therefore not clear a priori that the trade impacts of regulations are inefficient, or that removal of associated non-tariff measures that affect trade would achieve efficiency gains that would exceed the losses from weaker regulation.

The proposed comparative approach to NTMs allows for the identification of alternative ways to address a given regulatory problem. By systematically enumerating costs and benefits for all the different economic actors involved, an evidence-based approach can be followed that yields a solid basis for mutual exchange and identification of least-cost solutions. This approach gains particular importance in view of the rising occurrence of trade frictions about food safety and food quality (Josling et al. 2004).

The proposed methodology also opens possibilities for analytical work based on the newly proposed NTM classification by the MAST group.

By applying the proposed framework to several cases with different policy settings and in different markets will gain insights into its applicability and limitations under a variety of circumstances, and whether the model is able to provide reliable estimates of all benefits and costs. Two papers (TAD/TC/CA/WP(2008)4) and TAD/TC/CA/WP/RD(2008)1 prepared for the Joint Working Party on Agriculture and Trade discuss the data availability and selection of possible cases for further analysis. 


\section{Bibliography}

Adamson, D., and D. Cook. (2007). "Re-examining economic options for import risk assessments," Mimeo paper presented at the 2007 AARES annual Meetings, Queenston, NZ.

Akerlof, G. (1970). The market for 'lemons'; Qualitative uncertainty and the market mechanism. Quarterly Journal of Economics, 84, 488-500.

Alfnes, F., and K. Rickertsen (2003). European Consumers' Willingness to Pay for U.S. Beef in Experimental Auction Markets. American Journal of Agricultural Economics, 85:2 396.

Antle, J. (2000), "No such thing as free safe lunch: the costs of food safety regulation in the meat industry", American Journal of Agricultural Economics, Vol.82 No. 2, p.310-322.

Barrett, C.B., and Y.N. Yang. 2001. Rational incompatibility with international product standards, Journal of International Economics 54(1): 171-191.

Baumol W.J., and W.E. Oates. (1988). The Theory of Environmental Policy Cambridge University Press.

Beghin J. (2006), "Nontariff Barriers," in S. Darlauf and L. Blume, eds., The New Palgrave Dictionary of Economics, 2nd Edition, Palgrave Macmillan LTD, 2008: 126-129.

Bicknell, K., Wilen, J.E. and Howitt R.E. (1999). Public policy and private incentives for livestock disease control, Australian Journal of Agricultural and Resource Economics, 43, 501-521.

Blumenschein, K., G. Blomquist, M. Johannesson, N. Horn, and P. Freeman (2008). Eliciting Willingness to Pay Without Bias: Evidence from a Field Experiment. Economic Journal, 118, 114-137.

Boughner, D.S., H. de Gorter, and I. M. Sheldon. (2000). The Economics of Two-Tier Tariff-Rate Import Quotas in Agriculture, Agricultural and Resource Economics Review 29/1: 58-69.

Bureau, J. C., S. Marette, and A. Schiavina. Non-Tariff Trade Barriers and Consumers' Information: The Case of EU-US Trade Dispute on Beef . European Review of Agricultural Economics, 25-4 (1998): 437-462.

Buzby, J.C., T. Roberts, C.J. Lin, and J. MacDonald. (1996), Bacterial Foodborne Disease: Medical Costs and Productivity Losses, U.S. Department of Agriculture, Economic Research Service, Agricultural Economic Report 741.

CABI. CABI Aquaculture_Compendium available on line at: http://www.cabi.org/compendia/ac/index.asp.

-----. CABI Animal Health and Production Compendium, available on line at: http://www.cabi.org/compendia/ahpc/.

-----. CABI Crop Protection Compendium, available on line at: http://www.cabi.org/compendia/cpc/.

CABI Forestry Compendium, available on line at: http://www.cabi.org/compendia/fc/.

Casella, A. (1996). "Free Trade and Evolving Standards," chapter 3 in J.N. Bhagwati and R.E. Hudec (eds.) Fair Trade and Harmonization: Prerequisites for Free Trade? MIT press.

Centre for International Economics (2006). Feasibility of extending CoOL: A benefit cost analysis, Canberra \& Sydney: CIE.

Chang J., J. Lusk and B. Norwood (2008). "How Closely Do Hypothetical Surveys and Laboratory Experiments Predict Field Behavior?” Working paper, Oklahoma State University. 
Cheney, T. (2005), Distorted gravity: heterogeneous firms, market structure and the geography of international trade, mimeo, Massachusetts Institute of Technology (MIT), Cambridge/Massachusetts.

Chichilnisky, G. (1994). North-South Trade and the Global Environment, The American Economic Review, Vol. 84, No. 4 (Sep., 1994), pp. 851-874.

Costa-Font, M., J. M. Gil, and W. B. Traill (2008). "Consumer acceptance, valuation of and attitudes towards genetically modified food: Review and implications for food policy", Food Policy, 33, 99-111.

Costanza, Robert, Ralph d'Arge, Rudolf de Groot, Stephen Farber, Monica Grasso, Bruce Hannon, Karin Limburg, Shahid Naeem, Robert V. O'Neill, Jose Paruelo, Robert G. Raskin, Paul Sutton, Marjan van den Belt, 1997, The value of the world's ecosystem services and natural capital, Nature, vol. 387, May 15 1997, pp. 253-260.

Costello, C., M. Springborn, C. McAusland, and A. Solow. 2007. "Unintended biological invasions: Does risk vary by trading partner?" Journal of Environmental Economics and Management 54(3): 262-276.

Crespi J. and S. Marette. How Should Food Safety Certification Be Financed. American Journal of Agricultural Economics, 83, 4 (2001): 852-861.

Czubala, W., B Shepherd, and J.S. Wilson. 2007. "Help or Hindrance? The Impact of Harmonized Standards on African Exports," World Bank Policy Research Working Paper 4400, Washington DC.

Disdier, A.C., L. Fontagné, and M. Mimouni. 2008. The Impact of Regulations on Agricultural Trade: Evidence from SPS and TBT Agreements, American Journal of Agricultural Economics 90(2): 336-350

Eiswerth, M.E., and G.C. van Kooten. (2002), Uncertainty, Economics, and the Spread of an Invasive Plant Species, Amer. Journal of Agricultural Economics, 84 (5): 1317-1322.

Ferrantino, M. (2006), Quantifying the trade and economic effects of non-tariff measures, OECD Trade Policy working paper, no. 28, TD/TC/WP(2005)26/FINAL

Fisher, R. and P. Serra (2000), Standards and Protection, Journal of International Economics, 52, 377-400.

Fontagné, L., M. Mimouni and JM Pasteels (2005), Estimating the impact of environmental SPS and TBT on international trade, Integration and Trade Journal 22: 7-37.

Foster, W., and R. Just (1989), Measuring Welfare Effects of Product Contamination with Consumer Uncertainty. Journal of Environmental Economics and Management. 17, 266-283.

Fox, J., D. Hayes, and J. Shogren (2002), Consumer Preferences for Food Irradiation: How Favorable and Unfavorable Descriptions Affect Preferences for Irradiated Pork in Experimental Auctions, Journal of Risk and Uncertainty 24, 1, 75-95.

Freeman, A.M. (1993), Measuring Environmental and Resource Values. Theory and Methods, Resources for the Future, Washington D.C.

Fulponi, L. (2006), Private voluntary standards in the food system: The perspective of major food retailers in OECD countries, Food Policy 31, Issue 1:1-13.

Gandal, N., and O. Shy (2001), Standardization policy and international trade, Journal of International Economics 53(2): 262-282.

Garcia Martinez, M., A. Fearne, J.A. Caswell, and S. Henson. (2007), Co-regulation as a possible model for food safety governance: Opportunities for public-private partnerships, Food Policy 32: 299-314. 
Grothe, U., Deblitz, C. and S. Stegmann (2000), Total costs and environmental standards for selected agricultural products in Brazil, Germany and Indonesia: the impact on international competition, Quarterly Journal of International Agriculture 19(2000), No. 3, p: 299-318.

Hammitt, J. K. (2002). QALYs Versus WTP. Risk Analysis, 22:985-1001.

Harrington, W. and Portney, P.R. (1987), Valuing the Benefits of Health and Safety regulations, Journal of Urban Economics, 22, 1, pp 101-112.

Hayes, D., J. Shogren, Y. Shin, and J. Kliebenstein (1995), Valuing Food Safety in Experimental Auction Markets, American Journal of Agricultural Economics 77, 40-53.

Henry de Frahan, B., and M. Vancauteren. (2006), Harmonization of food regulations and trade in the Single Market: evidence from disaggregated data, European Review of Agricultural Economics 33(3): 337-360.

Horn, H., and P.C. Mavroidis (2006), “The WTO Dispute Settlement System 1995-2004: Some descriptive statistics,"Mimeo.

Huffman W.E, M.C. Rousu, J.F. Shogren, and A. Tegene (2003). The Public Good Value of Information from Agribusinesses on Genetically Modified Food, American Journal of Agricultural Economics 85, 1309-1315.

Huffman W.E, M.C. Rousu, J.F. Shogren, and A. Tegene (2007), The Effects of Prior Beliefs and Learning on Consumers' Acceptance of Genetically Modified Food, Journal of Economic Behavior \& Organization, 63, 193-206.

Hummels, D. (2001), “Time as a trade barrier”, mimeo, Purdue University. http://www.krannert.purdue.edu/centers/ciber/publications/pdf/00-007Hummels2.pdf

ITTO (2008), Towards increasing the comparability and acceptance of forest certification systems, ITTO Technical Series No 29, by Alan Purbawiyatna and Markku Simula, http://www.itto.or.jp/live/Live_Server/4092/TS29.pdf

Josling T., D. Roberts and D. Orden (2004). Food Regulation and Trade: Toward a Safe and Open Global System. Institute for International Economics, Washington DC, March 2004.

Jones, R.E., and R.W. Medd. (2000), Economic Thresholds and the Case for Longer Term Approaches to Population Management of Weeds, WeedTech. 14 (April-June ): 337-50.

Kee, H. L., A. Nicita. and M. Olarreaga. (2008). "Import Demand Elasticities and Trade Distortions," Review of Economics and Statistics (forthcoming).

Kompas, T. and T.N. Che (2003), “A Practical Border Quarantine Measure for Imported Livestock", International and Development Economics Working Papers (03-1), Crawford School of Economics and Government, Australian National University, Canberra.

Kompas, T., Che, T.N., Cao, L.Y. and Klijn, N. (2004), “Optimal Surveillance Measures Against an Imported Pest or Disease: An Application to Papua Fruit Fly in Australia", Australian Bureau of Agricultural and Resource Economics, Canberra.

Kopp, R.J., Krupnick, A.J. and Toman, M. (1997), “Cost Benefit Analysis and Regulatory Reform: An Assessment of the Science and the Art”, Discussion paper 97-19, Resources for the Future, Washington D.C.

Lagerkvist, C.J., Carlsson, F., \& Viske, D. (2006), Swedish consumer preferences for animal welfare and biotech: A choice experiment. AgBioForum, 9(1), 51-58. Available on http://www.agbioforum.org.

Landelfeld, J.S. and Seskin, E.P. (1982), The Economic Value of Life: Linking Theory and Practice, American Journal of Public Health, 6, 555-66.

Larson, B. E. (2003), Eco-labels for credence attributes: the case of shade-grown coffee, Environment and Development Economics, 8: 529-547. 
Levine, J.M., and C. M. D'Antonio (2003), "Forecasting Biological Invasions with Increasing International Trade," Conservation Biology 17 (1): 322-326.

Levitt, S.D. and List, J.A., 2007. What Do Laboratory Experiments Tell Us About the Real World. Journal of Economic Perspective, 21,153-174.

Lichtenberg, E., D.D. Parker, and D. Zilberman (1988). "Marginal Analysis of Welfare Costs of Environmental Policies: The Case of Pesticide Regulation.” American Journal of Agricultural Economics, 70(4):867-74.

List J.A., (2007). Field Experiments: A Bridge between Lab and Naturally Occurring Data. Advances in Economic Analysis \& Policy 6(2), Article 8. http://www.bepress.com/bejeap/advances/vol6/iss2/art8 (Access April 2007).

Lusk, J.L., Fox J.A. (2003). Value Elicitation in Retail and Laboratory Environments. Economics Letters, 79, 27-34.

Lusk, J.L., Roosen, J., Fox, J.A. (2003). Demand for beef from cattle administered growth hormones or fed genetically modified corn: a comparison of consumers in France, Germany, The United Kingdom and The United States. American Journal of Agricultural Economics 85, 16-29.

Lusk J., J. Brown, T. Mark, I. Proseku, R. Thompson and J. Welsh (2006a). "Consumer Behavior, Public Policy, and Country-of-Origin Labeling," Review of Agricultural Economics, 28(2), 284-292.

Lusk J., W. B. Traill, L. O. House, C. Valli, S. R. Jaeger, M. Moore, B. Morrow (2006b). Comparative Advantage in Demand: Experimental Evidence of Preferences for Genetically Modified Food in the United States and European Union, Journal of Agricultural Economics, 57(1), 1-21.

Lusk, J.L., Shogren J.F (2007a). Experimental Auctions. Methods and Applications in Economic and Marketing Research. Cambridge University Press, Cambridge, UK.

Lusk, J.L., Shogren J.F (2007b). Chapter 1. Introduction. in Experimental Auctions. Methods and Applications in Economic and Marketing Research. Cambridge University Press, Cambridge, UK. http://www.cambridge.org/catalogue/catalogue.asp?isbn=9780521671248\&ss=exc (access available July 2008).

Maertens, M., and J.F.M. Swinnen. (2009). "Trade, Standards, and Poverty: Evidence from Senegal," World Development 37, Issue 1, January 2009, Pages 161-178

Maertens, M., L. Dries, F.A. Dedehouanou, and J.F.M. Swinnen. 2007. "High-value supply chains, food standards and rural households in developing countries.” in J.F.M. Swinnen, ed. Global supply chains, standards and the poor. Cabi Publishing, Wallingford.

Marette S. (2007) Minimum Safety Standard, Consumer's Information and Competition, Journal of Regulatory Economics, 32, 259-285.

Marette, S., and J.C. Beghin (2007), “Are Standards Always Protectionist?” CARD Working Paper \#07-WP 450, June.

Marette S. (2008). Standards and Labels, Economics Bulletin, 12, 2 (2008) 1-7.

Marette S., J. Roosen, S. Blanchemanche, P. Verger (2008a). The Choice of Fish Species: An Experiment Measuring the Impact of Risk and Benefit Information. Journal of Agricultural and Resource Economics, 33, 1-18.

Marette S., J. Roosen, S. Blanchemanche (2008b). Taxes and Subsidies to Change Eating Habits when Information is not enough: An Application to Fish Consumption. Journal of Regulatory Economics, 34, 119-143. 
Marette S., J. Roosen, S. Blanchemanche (2008c). Health Information and Substitution between Fish: Lessons from Laboratory and Field Experiments. Food Policy, 33, 197-208.

Marra, M.C., \& Piggott, N.E. (2006). The value of non-pecuniary characteristics of crop biotechnologies: A new look at the evidence. In Just, Alston, and Zilberman (Eds.), Regulating Agricultural Biotechnology: Economics and Policy (pp.145-178). New York: Springer-Verlag Publishers.

Maskus, K., Otsuki, T. and J.S. Wilson (2005), The costs of compliance with product standards for firms in developing countries: an econometric study, working paper 3590, World Bank, Washington DC.

MAST (Multi-agency support team), (2008), First Progress Report to the Group of Eminent Persons on Non-tariff Barriers, (June 2008). Mimeo, Geneva, UNCTAD.

Moenius, J. (1999), "Information versus Product Adaptation: The role of Standards in Trade." Working paper, University of California, San Diego.

, (2006), "The Good, the Bad and the Ambiguous: Standards and Trade in Agricultural Products." Paper presented at IATRC Summer symposium "Food Regulation and Trade: Institutional Framework, Concepts of Analysis and Empirical Evidence”, Bonn, Germany, 2830 May.

Melitz, M. (2003), The Impact of Trade on Intra-Industry Reallocations and Aggregate Industry Productivity, Econometrica, 71(6), pp.1695 - 1725.

Morall J. (2003), Saving Lives: A review of the Record. Journal of Risk and Uncertainty, 27: 221237.

Napolitano F., C. Pacelli, A. Girolami and A. Braghieri (2008), Effect of Information About Animal Welfare on Consumer Willingness to Pay for Yogurt, Journal of Dairy Science. 91:910-917

Noussair, C., S. Robin, and B. Ruffieux (2002). Do Consumers Not Care about Biotech Foods or Do They Just Not Read the Labels? Economics Letters 75: 47-53.

Nimon, W. and J. Beghin (1999), Are Eco-Labels Valuable? Evidence From The Apparel Industry, American Journal of Agricultural Economics 81(3): 801-811.

Polinsky A. M., Rogerson, W. (1983). Products Liability and Consumer Misperceptions and Market Power. The Bell Journal of Economics 14, 581-89.

OECD (2002a), Agriculture and Trade Liberalisation: Extending the Uruguay Round Agreement. Paris: OECD publication services.

OECD (2002b), Alternative liberalisation scenarios and their impacts on quota rents and tariff revenues in selected OECD agricultural markets COM/AGR/TD/WP(2002)23/FINAL 19-Nov2002.

OECD (2006a), Final report on private standards and the shaping of the agro-food system, Working Party on Agricultural Policies and Markets. AGR/CA/APM(2006)9/FINAL.

OECD (2006b), Private standard schemes and developing country access to global value chains: challenges and opportunities emerging from four case studies, Working Party on Agricultural Policies and Markets (October 2006), AGR/CA/APM(2006)20.

OECD (2006c), Cost-Benefit Analysis and the Environment: Recent developments, (Authored by David Pearce, Giles Atkinson and Susana Mourato), Paris: OECD Publishing.

OECD (2007a), Scoping paper: economic assessment of non-tariff measures in agro-food trade, Joint Working Party on Agriculture and Trade (October 2007). TAD/TC/CA/WP(2007)3.

OECD (2007b), Documentation of the AGLINK_COSIMO model, Working Party on Agricultural Policies and Markets, AGR/CA/APM(2006)16/FINAL 
OECD (2008a), Interaction of public and private standards in the food chain, Working Party on Agricultural Policies and Markets, May 2008. AGR/CA/APM(2006)21/REV2.

OECD (2008b), A review of methods for quantifying the trade effects of standards in the agri-food sector, Joint Working Party on Trade and Agriculture (June 2008), TAD/TC/CA/WP(2007)1/REV1.

OECD (2008c), Identifying trade facilitating and trade limiting non-tariff measures - what does the data tell us? Joint Working Party on Trade and Agriculture (October 2008) (TAD/TC/CA/WP(2008)5.

OFIMER (2007), Office National Interprofessionnel des Produits de la Mer et de L'Aquaculture. Commerce Extérieur des Produits de la Pêche et de I'Aquaculture. Bilan Annuel 2007. Paris.

Orden, D., and E. Romano (1996). "The Avocado Dispute and Other Technical Barriers to Agricultural Trade Under NAFTA," Invited paper presented at the conference "NAFTA and Agriculture: Is the Experiment Working," San Antonio, TX. November.

Otsuki, T., J.S. Wilson, and M. Sewadeh (2001), What Price Precaution? European Harmonisation of Aflatoxin Regulations and African Groundnut Exports, European Review of Agricultural Economics 28(3):263-283.

Paarlberg, P.L., and J.G. Lee. (1998),Import restrictions in the presence of a health risk: an illustration using FMD. American Journal of Agricultural Economics Vol. 80(1): 175-183.

Pendell, D.L., J. Leatherman, T.C. Schroeder, and G.S. Alward. (2007), The Economic Impacts of a Foot-And-Mouth Disease Outbreak: A Regional Analysis, Journal of Agricultural and Applied Economics 39 (October): 19-33.

Peterson, E.B., and D. Orden. (2008), Avocado Pests and Avocado Trade, American Journal of Agricultural Economics, 90: 321-335.

Piggott, N.E., and M.C. Marra. (2007), The Net Gain to Cotton Farmers of a Natural Refuge Plan for Bollgard II® Cotton, AgBioForum, 10(1): 1-10.

Pimentel, D., R. Zuniga, and D. Morrison. (2005). “ Update on the environmental and economic costs associated with alien-invasive species in the United States." Ecological Economics 52 : $273-288$.

Pimentel, D., L. Lach, R. Zuniga, and D. Morrison (2000). "Environmental and Economic Costs of Nonindigenous Species in the United States.” Biosci. 50 (January): 53-65.

Pollak, R.A. (1995). Regulating risks, Journal of Economic Literature, March, 33, 1, pp 179-91.

Pollak, R.A. (1998). Imagined risks and cost-benefit analysis, American Economic Review, Papers and Proceedings, 88, 2, pp 376-79.

Qaim, M., and I. Matuschke. (2005). Impacts of genetically modified crops in developing countries: a survey, Quarterly Journal of International Agriculture Vol. 44 No. 3: 207-227

Rau M. L, and F. van Tongeren. (2007). Modeling differentiated quality standards in the agri-food sector: the case of meat trade in the enlarged EU. Agricultural Economics, 37: 305-315.

Rau M. L, and F. van Tongeren. (2008). "Heterogeneous firms and homogenising standards in agri-food trade- the Polish meat case". Paper prepared for the European Trade Study Group conference, Warsaw, September 2008.

Reardon, T., Timmer, C.P., Barrett, C. and J. Berdegué (2003), The Rise of Supermarkets in Africa, Asia, and Latin America, American Journal Agricultural Economics 85(5): 1140-1146.

Rozan, A., Stenger, A., Willinger, M., (2004). Willingness-to-Pay for Food Safety: An Experimental Investigation of Quality Certification on Bidding Behaviour. European Review of Agricultural Economics, 31(4), 409-425. 
Rousu, M.C., W.E. Huffman, J.F. Shogren, and A. Tegene (2004). "Estimating the Public Value of Conflicting Information: The Case of Genetically Modified Foods." Land Economics 80(1): 125-135.

Rousu, M.C., W.E. Huffman, J.F. Shogren, and A. Tegene (2007). "Effects and Value of Verifiable Information in a controversial market: Evidence from Lab Auctions of Genetically Modified Food.” Economic Inquiry, 45(3): 409-432.

Shogren J.F., Fox, J.A., Hayes, D.J., Roosen, J. (1999). Observed Choices for Food Safety in Retail, Survey, and Auction Markets. American Journal of Agricultural Economics 81(5), 1192-1199.

Shogren J. (2006). Valuation in the Lab. Environmental \& Resource Economics 34, 163-172.

Sobolevsky A., G. Moschini and H. Lapan (2005). "Genetically Modified Crops and Product differentiation: Trade and Welfare Effects in the Soybean Complex". American Journal of Agricultural Economics 83(1): 133-149.

Stoneham, G., V.Chaudhri,, A.Ha and L. Strappazzon (2003), Auctions for conservation contracts: an empirical examination of Victoria's BushTender trial, Australian Journal of Agricultural and Resource Economics. Vol. 47 (4): 477-500.

Sutton, J. (1991), Sunk Costs and Market Structure: Price Competition, Advertising, and the Evolution of Concentration. MIT Press, Cambridge, MA.

Swinton, S.M., D.D. Buhler, F. Forcella, J.L. Gunsolus, and R.P. King. (1994). "Estimation of Crop Yield Loss Due to Interference by Multiple Weed Species." Weed Science Vol. 42 (1): 103-109.

Taylor, C.R., and O.R. Burt. "Near-optimal Management Strategies for Controlling Wild Oats in Spring Wheat." Amer. J. Agr. Econ. 66(February 1984):50-60.

Teisl, M., N. Bockstael, and A. Levy (2001). "Measuring the Welfare Effects of Nutrition Information." American Journal of Agricultural Economics 83(1): 133-149.

Teisl M., B. Roe and R. Hicks (2002). Can Eco-labels Tune a Market? Evidence from DolphinSafe Labelling. Journal of Environmental Economics and Management. 43:339-359

Treasury Board of Canada (2007). Canadian Cost-Benefit Analysis Guide. Regulatory Proposals. http://www.regulation.gc.ca/documents/gl-ld/analys/analys01-eng.asp

Wansink B., S. Sonka and C. Hasler (2004). Front-Label Health Claims: When Less is More. Food Policy, 29: 659-667.

Wilson, J.S., and T. Otsuki. 2004b. "Standards and Technical Regulations and Firms in Developing Countries: New Evidence from A World Bank Technical Barriers to Trade Survey," The World Bank, June, preliminary draft.

Wilson N.L. and J. Anton (2006). Combining risk Assessment and Economics in Managing a Sanitary-Phytosanitary Risk. American Journal of Agricultural Economics, 88, 194 - 202.

Wolfenbarger, L.L., and P.R. Phifer. (2000). "The Ecological Risks and Benefits of Genetically Engineered Plants," Science 290: 2088-93.

Yue, C., Beghin, J.C. and H.H. Jenson (2006), "Tariff equivalent of technical barriers to trade with imperfect substitution and trade costs", American Journal of Agricultural Economics, 88(4), page: $947-960$. 


\section{Appendix 1:}

\section{The MAST Classification of NTMs}

\section{A000 SANITARY AND PHYTOSANITARY MEASURES}

Classification of Non-Tariff Measures (version June 2008)

A100 Voluntary standards

A110 International Standards

A111 Production Process standards

A112 Product characteristics standards

A119 International Standards, n.e.s.

Sanitary and phytosanitary measures include laws, decrees, regulations, requirement, standards and procedures to protect human, animal or plant life or health.

Rules, guidelines or characteristics for products or processes and production methods, which are designed to protect human, animal and plant health and life.(e.g. composition, quality and hygiene), approved by recognized bodies at international, national or sub-national levels, or those set established by private companies. Voluntary standards do not have the authority of law.

Standards developed by international standards organisations. By definition, international standards are suitable for universal, worldwide use.

Standards defining processes for the production chain that will contribute to the safety and suitability of products. Standards defining the characteristics requested for products (e.g. size, colour, composition and quality) and contribute to the safety and suitability of products.

In general, each country or economy has a single recognized Standards Body (NSB). SPS allows countries to set their own standards which must be based on science. Applications of these rules must be limited to the extent necessary to protect human, animal or plant life or health. These rules should not be used arbitrarily or unjustifiably to discriminate between countries where identical or similar conditions prevail.

Standards defining processes for the production chain that will contribute to the safety and suitability of products These will rule the characteristics requested for products (e.g. size, colour, composition and quality) and will contribute to the safety and suitability of products.

Standards that may be imposed by a state or region within a country imposing extra requirements beyond national standards.

Standards defining processes for the production chain that will contribute to the safety and suitability of products. Standards defining the characteristics requested for products (e.g. size, colour, composition and quality) and contribute to the safety and suitability of products. 
A139 Subnational Standards, n.e.s.

A140 Private Standards*

A200 Sanitary and phytosanitary regulations

A210 Labelling, Marking and Packaging requirements

A211 Labelling requirements

A212 Marking requirements

A213 Packaging requirements

A220 Traceability requirements

A221 Origin of materials and parts

A222 Processing history

A223 Distribution and location of products after delivery

A229 Traceability requirements, n.e.s.

A230 Tolerance limits for residues and contaminants, or restricted use of certain substances

A231 Tolerance limits for residues of or contamination by certain substances in foods and feeds

\author{
A232 Restricted use of certain substances in \\ foods and feeds
}

Standards demanded by private entities, such as organizations representing supermarket chains and other bodies. (e.g. pesticide regulations, traceability and general hygiene of foodstuffs).

Sanitary and phytosanitary regulations include laws, decrees, requirements and procedures to protect human, animal or plant life or health. Compliance is mandatory. Measures regulating the kind, colour and size of printing on consumer packages and labels and defining the information that may or should be provided to the consumer which is directly related to food safety.

Labelling is any written, electronic, or graphic communication on the consumer packaging or on a separate but associated label.

Measures defining the information for transport and customs, that the transport/distribution packaging of goods should carry, which are directly related to food safety. Measures regulating the mode in which goods must be or cannot be packed, in conformity with the importing country handling equipment or for other reasons, and defining the packaging materials to be used, which is directly related to food safety.

Traceability is the disclosure of information regarding the origin of live animals and animal products as well as for agricultural products, including product processing history, and the distribution and location of the product after delivery. It aims to track through all phases of production and distribution.

Description of geographical origin of animals, plants and their derivative products.

Description of all stages of production

Description of transport, handling and storage of products after the production is finished

Maximum concentration of residue levels permitted (MRLs) on food, feed, wood, plants etc., or restriction on the use of certain substances as ingredients

Maximum Residue Limits (MRL) for toxic and other harmful substances and contaminants that enter the product during the production and/or distribution processes (e.g. insecticides, heavy metals, POPs and chemicals generated during processing such asacryl amide).

Restriction on the use of certain substances as ingredients, which are therefore reasonably expected to exist in the final product. As a result, their specification is also important to prevent the risks arising from their use 
A240 Regulation of foods or feeds derived from, or produced using genetically modified organisms (GMO)

A250 Hygienic requirement

A260 Disease prevention measuresA261 Restriction/prohibition in case of outbreak of infectious diseases

A262 Quarantine requirement

A270 Regulations on productions processes:

A271 Plant growth processes

A272 Animal raising or catching processes

A273 Food and feed processing, including storage and transport

A279 Regulations on productions processes, n.e.s.

\section{A280 Geographical restrictions}

A290 Sanitary and Phytosanitary regulations n.e.s.

A300 Conformity assessment related to SPS

\section{A310 Certification requirement}

A311 Certification by government agencies of the countries of origin

A312 Certification by local agencies in the destination market

A320 Lack of recognition

A321 Lack of acceptance of internationally recognized accredited conformity assessment bodies
These regulations may include labelling and authorization requirement or outright prohibition.

Restrictions to avoid contamination by microorganisms and parasites in foods and feeds that cover production, manufacturing, transport and storage conditions. Includes post-harvest treatment and pathogen controls

Measures to protect animals, humans and plants from any infectious/contagious diseases. Covers restrictions other than quarantine requirements. Measures included in this category are typically more of an ad-hoc and time-bound nature

Requirement to quarantine imports for a certain period. It is not a prohibitive measure. Quarantine supposes also quarantine fees, inspection fees, veterinary fees, boarding, fumigation etc.

This group of entries registers safety regulations relating to the production process (such as for example HACCP). It covers primary production (plant \& animals) and processing. National regulations that provide that only foods produced under certain code of practices can be accepted for sale are also included.

Prohibition on imports of specified products from countries or regions due to presence of phytosanitary hazards (e.g. insects, mites, plant pathogens)

Control, inspection and approval procedure, including procedures for sampling, testing and inspection, evaluation, verification and assurance of conformity; and accreditation and approval

Certification requirements either in the exporting or importing country

Requirement to obtain certifications from the exporting country.

Requirement to obtain certifications from the importing country.

Certifications issued by a country or authority are not recognized by the importing country.

International certifications are not recognized by the importing country. 
A322 Lack of acceptance of certificates of conformity assessment bodies issued in the country of origin

A323 Lack of acceptance of Self Declaration of Conformity (SDoC)

A329 Lack of recognition, n.e.s.

A330 Testing requirement

A340 Inspection and clearance requirement

A350 Registration requirement

A360 Repetition in destination market of identical tests for same or equivalent regulations

A370 Translation requirement for reports or certificates

A380 Requirement to pass through specified entry point or customs

A390 Conformity assessment related to SPS n.e.s.

A900 Sanitary and phytosanitary measures, n.e.s

BO00 TECHNICAL BARRIERS TO TRADE

B100 Voluntary standards

B110 International Standards

B111 Production Process standards

B112 Product characteristics standards

B113 Management system standards

B119 International Standards, n.e.s.
Certifications from exporters are not recognized by the importing country.

SDoC: procedure by which a supplier provides a written assurance that a product conforms to specified requirements

Includes sampling requirement and are usually associated to testing or laboratory fees

Imports require inspection and/or clearance to be accepted. Inspection can be done by public or private entities.

Importers may need to be registered in the importing country. It is often the case for sensitive products such as medicines and/drugs. Exporters need to contact a registered importer.

For a given regulation, a same test must be performed within a destination country at national, regional and/or local entry points

Documents must be translated to the language of the destination countries

Certain goods must be cleared at a specific entry point within a destination country for availability of testing or inspection facility

Technical barriers to trade (TBT) are regulations/standards referring to technical specification of products and conformity assessment systems thereof Rules, guidelines or characteristics for products or processes and production methods (e.g. size, colour, composition, quality, security and safety), approved by a recognized bodies at international, national or sub-national levels, or those established by private companies.

Compliance is not mandatory as voluntary standards do not have the authority of law.

Are standards developed by international standards organisations? By definition, international standards are suitable for universal, worldwide use.

Standards defining processes for the production chain that will contribute to the security, safety and suitability of products.

Standards defining the characteristics requested for products (e.g. size, colour, components and quality) and contribute to the security, safety and suitability of products. Also includes those related to product performance. Standards that provide requirements or give guidance on good management practice, establishing a framework on production (e.g. the quality system of a manufacturing business might include looking at more efficient manufacturing processes or speeding up distribution). 
B120 National Standards

B121 Production process standards

B122 Product characteristics standards

B129 National Standards, n.e.s.

B130 Subnational Standards

B131 Production process standards

B132 Product characteristics standards

B139 Subnational Standards, n.e.s. B140 Private Standards*

\section{B200 Technical regulations}

B210 Labelling, Marking and Packaging requirements

B211 Labelling requirements

\section{B212 Marking requirements}

B213 Packaging requirements

B220 Traceability requirements

B221 Origin of materials and parts

B222 Processing history

B223 Distribution and location of products after delivery

B229 Traceability requirements, n.e.s.B230

Tolerance limits for residues or restricted use of certain substances
Technical standards to be applied at National Level regulating product technical characteristics and production processes

Standards defining processes for the production chain that will contribute to the security, safety and suitability of products.

Standards defining the characteristics requested for products (e.g. size, colour, components and quality) and contribute to the security, safety and suitability of products. Also includes those related to product performance.

Standards that may be imposed by a state or region within a country imposing extra requirements beyond national standards.

Standards defining processes for the production chain that will contribute to the security, safety and suitability of products.

Standards defining the characteristics requested for products (e.g. size, colour, components and quality) and contribute to the security, safety and suitability of products. Also includes those related to product performance. Standards demanded by non-governmental bodies, such as private companies. (e.g. computer software standards or electric appliances).

Measures regulating the kind, colour and size of printing on packages and labels and defining the information that may or should be provided to the consumer. Labelling is any written, electronic, or graphic communication on the packaging or on a separate but associated label, or on the product itself.

Measures defining the information for transport and customs, that the transport/distribution packaging of goods should carry.

Measures regulating the mode in which goods must be or cannot be packed, in conformity with the importing country handling equipment or for other reasons, and defining the packaging materials to be used.

Traceability is the disclosure of information regarding the origin of materials and parts, including product processing history, and the distribution and location of the product after delivery. It aims to track through all phases of production and distribution.

Description of geographical origin of materials and parts. Description of all stages of production

Description of transport, handling and storage of products after the production is finished

Maximum concentration or restrictions to use certain substances 
B231 Tolerance limits for residues or contamination by certain substances

B232 Restricted use of certain substances

B240 Regulation on genetically modified organisms (for reasons other than food safety) B250 Identity requirement

B260 Environment-specific requirement

B270 Other product characteristics

requirements

B280 Other production process requirements

B290 Technical regulations n.e.s.

B300 Conformity assessment related to TBT

\section{B310 Certification requirement}

B311 Certification by government agencies of the countries of origin

B312 Certification by local agencies in the destination market

B320 Lack of recognition

B321 Lack of acceptance of internationally recognized accredited conformity assessment bodies

B322 Lack of acceptance of certificates of conformity assessment bodies issued in the country of origin

B323 Lack of acceptance of Self Declaration of Conformity (SDoC)

B329 Lack of recognition, n.e.s.B330 Testing requirement

B340 Inspection and clearance requirement

B350 Registration requirement

B360 Repetition in destination market of identical tests for same or equivalent regulations

B370 Translation requirement for reports or certificates
Maximum limits for toxic and other harmful substances and contaminants that enter the product during the production process.

Restriction on the use of certain substances as components or additives, which are therefore reasonably expected to exist in the final product. As a result, their specification is also important to prevent the risks arising from their use Restriction on imports if genetically modified organisms are used in the production.

Conditions to be satisfied in order to identify a product with a certain denomination (e.g. minimum, percentage content of an ingredient that gives the name to the final product such as cocoa content in "chocolate")cocoa)

Conditions or requirements that aim to prevent environmental damage or ensure protection of the environment.

Control, inspection and approval procedure, including procedures for sampling, testing and inspection, evaluation, verification and assurance of conformity, and accreditation and approval

Certification requirements either in the exporting or importing country

Requirement to obtain certifications from the exporting country

Requirement to obtain certifications from the importing country

Certifications issued by a country or authority are not recognized by the importing country.

International certifications are not recognized by the importing country.

Certifications from exporters are not recognized by the importing country.

SDoC: procedure by which a supplier provides a written assurance that a product conforms to specified requirements Includes sampling requirement and are usually associated to testing or laboratory fees

Imports require inspection and/or clearance to be accepted. Inspection can be done by public or private entities. Importers may need to be registered in the importing country. It is often the case for sensitive products that may be related to security issues. Exporters need to contact a registered importer.

For a given regulation, a same test must be performed within a destination country at national, regional and/or local entry points

Documents must be translated to the language of the destination countries 
B380 Requirement to pass through specified entry point or customs

B390 Conformity assessment related to TBT n.e.s.

B900 Technical barriers to trade, n.e.s.
Certain goods must be cleared at a specific entry point within a destination country for availability of testing or inspection facility

\section{COOO OTHER TECHNICAL MEASURES}

\section{C100 Pre-shipment inspection} C200 Special custom formalities not related to
SPS/TBT

C210 Documentation requirement

\section{C220 Direct consignment requirement}

C230 Requirement to pass through specified port of customs

\section{C240 Transportation restrictions}

C241 Restrictive Air transportations regulations C242 Restrictive Sea transportations regulations C243 Restrictive land transportations regulations C290 Special custom formalities not related to SPS/TBT, n.e.s. C900 Technical Measures n.e.s.
A physical inspection of goods before they are shipped in the country of export, which establishes the exact nature of the goods. The inspection assures that the goods are in accordance with the accompanying documents that specify their customs tariff code, quality, quantity and price. Formalities to be fulfilled at the customs, which are not related to the administration of SPS/TBT measures Requirement to produce any document used to declare shipments to Customs in the country of import Goods must be shipped directly from the country of origin, without stopping at a third country

Goods must pass through a designated entry point and/ or customs office, which might slow down the import clearance process.

Particular transportations conditions, norms or laws stipulated by National Authorities of each country that may be considered as restrictive
D100 Administrative pricing

D110 Minimum import prices

\section{D000 PRICE CONTROL MEASURES}

Price control measures are implemented to control the prices of imported articles in order to: support the domestic price of certain products when the import price of these goods are lower; establish the domestic price of certain products because of price fluctuation in domestic markets, or price instability in a foreign market; and counteract the damage resulting from the occurrence of "unfair" foreign trade practices.

By administrative price fixing, the authorities of the importing country take into account the domestic prices of the producer or consumer; establish floor and ceiling price limits; or revert to determined international market values. There may be different price fixing methods, such as minimum import prices or prices set according to a reference

Pre-established import price below which imports cannot take place 
D120 Reference prices and other price controls

D190 Administrative pricing n.e.s.

D200 Voluntary export price restraint

D300 Variable charges

D310 Variable levies

D320 Variable components

D390 Variable charges n.e.s

D400 Antidumping measures

D410 Antidumping investigations

\section{D420 Antidumping duties}

Pre-established import price which authorities of the importing country use as reference to set a floor or ceiling price

A Voluntary export price restraint is an arrangement in which the exporter agrees to keep the price of his goods above a certain level.

Variable charges are taxes or levies aimed at bringing the market prices of imported agricultural and food products in line with the prices of corresponding domestic products 2 . Primary commodities may be charged per total weight, while charges on processed foodstuffs can be levied in proportion to the primary product contents in the final product. These charges include:

The rate of tax varies inversely with the price of imports. These charges are applied mainly to primary products. It may be called flexible import fee.

The tax includes a fixed component and a variable component. These charges are applied mainly to processed products where the variable part is applied on the primary products or ingredients included the final product. It may be called compensatory element.

Antidumping measures are taken against a dumping action of an exporter. It is considered that dumping takes place when a product is introduced into the commerce of an importing country at less than its normal value, i.e. if the export price of the product exported is less than the comparable price, in the ordinary course of trade, for the like product when destined for consumption in the exporting country.

Antidumping investigations are initiated either following a complaint by local producers of similar goods or selfinitiated by importing country authorities when they have cause to believe that dumping may be materially injurious to national competing producers or third parties' exporters. Provisional duties may be applied during the investigation. Antidumping duties are levied on certain goods originating from specific trading partner(s) to offset the dumping margin. Duty rates are generally enterprise-specific. 


\section{D430 Price undertakings}

D500 Countervailing measures

D510 Countervailing investigations

\section{D520 Countervailing duties}

\section{D530 Price undertakings}

D600 Safeguard duties
Undertakings to increase the export price may be offered by exporters to avoid the imposition of antidumping duties. Under WTO rules, prices can be negotiated for this purpose, but only after the dumping has been proved.
Countervailing measures are intended to offset any direct or indirect subsidy granted by authorities in the exporting country. These may take the form of countervailing duties or undertakings by the exporting firms or by authorities of the subsidizing country.

Countervailing investigations are initiated either following a complaint by local producers of similar goods or selfinitiated by the importing country authority to determine whether the imported goods are subsidized and cause material injury.

Duties levied on certain goods to offset the amount of subsidization granted by the exporter on the production or trade of these goods, when the subsidy is assumed to hurt domestic industry.

Undertakings to increase the export price may be offered by exporters to avoid the imposition of countervailing duties. Under WTO rules, prices can be negotiated for this purpose, but only after the injurious effect of the subsidy has been proved.

Emergency and/or temporary duties imposed as a safeguard action. A country may take a "safeguard" action (i.e., restrict imports of a product temporarily) to protect a specific domestic industry from an increase in imports of any product which is causing, or which is threatening to cause, serious injury to the domestic industry that produces like or directly competitive products.

Seasonal duties are applicable at certain times of the year, usually in connection with agricultural products.

D900 Price control measures n.e.s.

E000 QUANTITY CONTROL MEASURES

E100 Non-automatic licence
Quantity control measures are aimed at restraining the quantity of goods that can be imported, regardless of whether they come from different sources or one specific supplier. These measures can take the form of restrictive licensing, fixing of a predetermined quota, or through prohibitions.

(Most quantity control measures are formally prohibited by the GATT 1994, but can be applied under specifically determined circumstances (Article XI))

This licence is and import licence, which is not granted automatically. The licence may either be issued on a discretionary basis or may require specific criteria to be met before it is granted. 
E110 Licence with no specific ex-ante criteria

E120 Licence for specified use

E130 Licence linked with local production

E140 Licence combined with or replaced by special import authorization

E150 Licence for non-economic reasons

E151 Licence for political reasons

E159 Licence for non-economic reasons, n.e.s. E190 Non-automatic licensing n.e.s.

E200 Quotas

E210 Global quotas

E211 Unallocated quotas

E212 Allocated to exporting countries

E220 Bilateral quotas

E230 Seasonal quotas

E240 Quotas linked with purchase of local goods

E250 Quotas for non-economic reasons

E251 Quota for political reasons

E259 Quotas for non-economic reasons, n.e.s.
This licence, which is sometimes also referred to as a discretionary licence, is issued at the discretion of the issuing authority.

This licence is limited to operations generating anticipated benefit in important domains of the economy, such as export production, investment projects, etc.

This licence requires the compulsory linkage of imports with local market outputs.

In addition to or instead of a licence issued by the main licensing body (usually the ministry of trade), a special import authorization or an inscription in a register is required by a specialized authority which is coordinating a sector of the domestic economy (ministry of industry, ministry of agriculture, etc).

This licence is granted for political, religious reasons, or others, which hare not economic.

This licence is issued for political reasons rather than economic.

Quotas involve restricting the importation of specified products through the setting of a maximum quantity or value of goods authorized for import. The different forms of quotas are:

Global quotas are quotas established on the basis of the total quantity or value of imports of specific products, which can be filled on a first-come, first-served basis, or preallocated to different suppliers

Quotas that are filled on a first-come, first-served basis without allocating among exporters

Quotas which are pre-allocated among potential exporters Quotas of imports reserved for a specific country Quotas of imports for a given period of the year, usually set for certain agricultural goods.

Quotas defined as a percentage of the value of similar locally purchased goods.

Quotas for other reasons, rather than economic.

Quotas that are granted on the basis of political rather than economic reasons.

A system of multiple tariff rates applicable to a same product. The lower tariff rates apply up to a quota of imports, and the higher rates are charged on imports which exceed the quota amount. Quota may be defined in terms of quantity or value.

Compulsory linkage of imports (of materials or parts) with localproduction 15

E290 Quotas n.e.s.

E300 Prohibitions 
E310 Total prohibition (not for SPS reasons)

E320 Suspension of issuance of licences

E330 Seasonal prohibition

E340 Temporary prohibition

E350 Prohibition of importation in bulk

E360 Prohibition of products infringing patents or intellectual property rights

E370 Prohibition for non-economic reasons

E371 Prohibition for religious, moral or cultural reasons

E372 Prohibition for political reasons (Embargo)

E379 Prohibition for non-economic reasons,

n.e.s.

E390 Prohibitions n.e.s.

E400 Quantitative safeguard measures

E500 Export restraint arrangement

E510 Voluntary export restraint arrangements (VERs)

E511 Quota agreement

\section{E512 Consultation agreement}

E513 Administrative co-operation agreement

E590 Export restraint arrangements n.e.s. E900 Quantity control measures n.e.s.
Prohibition without any additional conditions or qualifications

The suspension of issuance of licences is a form of de facto prohibition. This situation may arise in cases related to short-term balance-of payments difficulties, or for other reasons.

Seasonal prohibition involves the prohibition of imports during a given period of the year. This is usually applied to certain agricultural products.

This prohibition is set only for a limited period of time, though it may not refer to a fixed ending date. It is usually for urgent matters.

Requirement that products must be imported in small packages or containers

Prohibition of copies, counterfeits or imitations of patented or trademarked products

Prohibitions for political, religious reasons, or others, which are not economic.

Some countries will prohibit the import, use, or possession of any item that is held to be contrary to the tenets of their Faith. This could include non religious materials, pork, alcohol products and illicit drugs or any other item that could be contrary to religion precepts. Any product that is related to pork even if it's not used as food like pig skin is still prohibited in some countries.

Prohibition of imports from a country or group of countries, applied for political reasons.

Measures having effect on quantitative restrictions. Quantitative safeguard measures are adopted when the government of the importing country wishes to prevent or remedy serious injuries resulting from a sudden increase of imports, or to facilitate adjustment.

An arrangement by which an exporter agrees to limit exports in order to avoid imposition of restrictions by the importing country, such as quotas, raised tariffs or any other import controls5. The arrangement may be concluded at either government or industry level.

Voluntary export restraints are arrangements made by government or industry of an exporting country to voluntarily limit exports in order to avoid imposition of mandatory restrictions by the importing country.

Export quotas, which a given exporting country would accept from an importing country to avoid imposition of mandatory restrictions

Agreement that includes provisions for consultation with a view to introducing restrictions under certain circumstances Agreement that includes provisions for administrative cooperation with a view to avoiding disruptions in bilateral trade. 
FO00 PARA-TARIFF MEASURES

F100 Customs Surcharges

F200 Additional taxes and charges

F210 Tax on foreign exchange transactions

F220 Stamp tax

F230 Import licence fee

F240 Consular invoice fee

F250 Statistical tax

F260 Merchandise handling or storing fees

F270 Tax on transport facilities

F280 Taxes and charges for sensitive product

categories

F290 Additional charges n.e.s.

F300 Internal taxes and charges levied on imports

F310 General sales taxes

F330 Taxes and charges for sensitive product categories F390 Internal taxes and charges levied on imports n.e.s.
Other measures that increase the cost of imports in a manner similar to tariff measures, i.e. by fixed percentage or by a fixed amount, calculated respectively on the basis of the value and the quantity, are known as para-tariff measures. Four groups are distinguished: customs surcharges; additional taxes and charges; internal taxes and charges levied on imports; and decreed custom valuation.

Customs surcharges, which are also called surtax or additional duty, is an ad hoc trade policy instrument to raise fiscal revenues or to protect domestic industries.

Additional charges, which are levied on imported goods in addition to customs duties and surcharges and which have no internal equivalent, and which comprise various taxes and fees. The category of additional charges includes the tax on foreign exchange transactions, stamp tax, import licence fee, consular invoice fee, statistical tax, tax on transport facilities and charges for sensitive product categories. Various other taxes, such as the export promotion fund tax, taxes for the special funds, the municipal tax, registration fee on imported motor vehicles, customs formality tax, etc., are classified as additional charges, n.e.s.

Article III of the GATT Agreement allows internal taxes to be applied to imports; however, these taxes should not be higher than those applied to similar domestic products.

The general sales tax levied on imports is the equivalent of those internal taxes that are applied to all or most products. Three types of internal axes can be distinguished: first, the one commonly known as sales tax, which is an ad valorem tax based on the gross receipts of sales of goods, collected at regular intervals from traders; secondly, the turnover tax or multiple sales tax, which is a tax imposed at more than one level of production and distribution and is based on gross receipts, resulting in a accumulation of taxes; thirdly, the value-added tax which is a modified turnover tax based on the net value added instead of on the gross receipts, avoiding accumulation of taxes and not affecting the price structure and the allocation of resources. 
F400 Decreed Customs Valuations

F900 Para-tariff measures n.e.s
G100 Advance payment requirement

G110 Advance import deposit

G120 Cash margin requirement

G130 Advance payment of customs duties

G140 Refundable deposits for sensitive product categories

G190 Advance payment requirements n.e.s.

G200 Multiple exchange rates

G300 Restrictive official foreign exchange allocation

G310 Prohibition of foreign exchange allocation

G320 Bank authorization

G330 Licence linked with non-official foreign exchange

G331 External foreign exchange

\section{G332 Importers' own foreign exchange}

G339 Licence linked with non-official foreign exchange, n.e.s.

G390 Restrictive official foreign exchange allocation, n.e.s.
Customs duties and other charges on selected imports can be levied on the basis of a decreed value of goods (the socalled "valeur mercuriale" in French). This practice is presented as a means to avoid fraud or to protect domestic industry. The decreed value de facto transforms an advalorem duty into a specific duty.
Financial measures are intended to regulate the access to and cost of foreign exchange for imports and define the terms of payment. They may increase import costs in the same manner as tariff measures.

Advance payment requirements related to the value of the import transaction and/or related import taxes, are made at the time an application is lodged, or when an import licence is issued. These payment requirements can consist of: Advance import deposits require the importer to deposit a percentage of the value of the import transaction before receiving the goods. No interest is paid on these deposits. Cash margin requirements entail depositing the total amount of the transaction value in a foreign currency, or a specified part of it, in a commercial bank, before the opening of a letter of credit.

Advance payment of custom duties entails paying all or part of the customs duties in advance; no interest in paid on these advance payments.

Refundable deposits are charges which are refunded when the used products or the containers they came in are returned to a collection system.

Varying exchange rates for imports, depending on the product category. Usually, the official rate is reserved for essential commodities while the other goods must be paid at commercial rates or occasionally by buying foreign exchange through auctions.

These restrictions are usually executed by the central bank in the form of permits, visas, authorizations, etc, and are intended to control import flows. Foreign exchange allocation is sometimes prohibited under this measure. No official foreign exchange allocations available to pay for imports.

A special authorization needs to be obtained from the central bank.

A licence is granted if official foreign exchange is not required.

A licence is granted only for imports required for technical assistance projects and other sources of external foreign exchange.

A licence is granted if importers have foreign exchange held in an overseas bank. 
G400 Regulations concerning terms of payment for imports

G500 Transfer delays, queuing

G600 Surrender requirement

G900 Finance measures n.e.s.
H000 ANTI-COMPETITIVE MEASURES

H100 Single channel for imports

H110 State trading administration, for importing H120 Sole importing agency

H190 Single channel for imports, n.e.s.

H200 Compulsory national service

H210 Compulsory national insurance

H220 Compulsory national transport

H290 Compulsory national service, n.e.s.

H900 Anti-competitive measures, n.e.s.
I000 EXPORT RELATED MEASURES

I100 Export taxes

I200 Export quantitative restriction

\section{I210 Export Prohibition}

I220 Export quotas

I230 Licensing or permit requirements to export

I240 Registration, tight regulation or restriction to export

I290 Export quantitative restrictions, n.e.s. the obtaining and use of credit (foreign or domestic) to finance imports.

Transfer delays and queuing relate to the maximum permitted delays between the date that goods have been delivered and the date of the final settlement of the imported goods (usually 90, 180 or 360 days for consumer goods and industrial inputs and two to five years for capital goods). Queuing takes place when the prescribed delays cannot be observed because of foreign exchange shortages, and when transactions are settled after a longer delay.

This requirement relates to the surrender of foreign exchange earnings to the central bank.
These regulations cover the terms of payment of imports and

Measures to grant exclusive or special preferences or privileges to one or more limited group of economic operators, for social, fiscal, economic or political reasons. The requirement that all imports, or imports of selected commodities, have to be channelled through state-owned agencies or state-controlled enterprises. The private sector is sometimes also granted exclusive import rights.

Compulsory national service consists of government-backed exclusive rights of national insurance and shipping companies on all or a specified share of imports.
Export-related measures are measures applied by the government of the exporting country on exported goods.

Export taxes/duties are taxes collected on goods or commodities by the government of the exporting country. Export taxes can be set either on a specific or an ad valorem basis

Restrictions to the quantity of goods exported to a specific country or countries by the government of the exporting country for reasons such as: shortage of goods in the domestic market; avoiding antidumping measures; or for political reasons.

Prohibition of exports of certain products Quotas that limit value or volume of exports. Exporters are required to obtain licensing or permit by the government of the exporting country to export products. Requirement to register products before being exported (for monitoring purposes) 


\section{I300 Certification}

I400 Inspection fee

I500 State trading administration

I600 Dual pricing schemes

I900 Export measures n.e.s.
Requirement by the exporting country to obtain sanitary, phytosanitary or other certification before the goods are exported

A fee levied by the government authority of exporting country to cover the cost of inspection for exporting products

All or parts of exports of selected commodities have to be channelled through specific enterprises identified by governments.

Different prices for products are applied depending on whether they are sold on domestic market or export markets.

\section{J000 TRADE-RELATED INVESTMENT \\ MEASURES \\ J100 Local content measures}

J200 Trade balancing measures

J900 Trade-related investment measures, n.e.s K000 DISTRIBUTION RESTRICTIONS*

LO00 RESTRICTION ON POST-SALES SERVICES*

M000 SUBSIDIES*
Requirement to use certain minimum levels of locally made component, which restrict the level of imported components.

Measures limiting the purchase or use of imported products by an enterprise to an amount related to the volume or value of local products that it exports

Restriction to limit and rule the way the products are distributed. It may be controlled through additional license or certification requirement.

Measures restricting producers of exported goods in exporting countries to provide post sales service in the importing country

Financial contribution by a government or government body to a production structure, being a particular industry or company, such as direct transfer of funds or potential transfer of funds (e.g. grants, loans, equity infusions), payments to a funding mechanism and income or price support.

\section{N000 GOVERNMENT PROCUREMENT RESTRICTIONS*}

Measures controlling the purchase of goods by government agencies, generally by preferring national providers
Intellectual property legislation covers patents, trademarks, industrial designs, lay-out designs of integrated circuits, copyright, geographical indications and trade secrets. Rules of origin cover laws, regulations and administrative determinations of general application applied by government of importing countries to determine the country of origin of goods. Rules of origin can restrict trade when it is difficult to determine the origin of the final product if raw materials and parts come from different countries. Rules of origin are important in implementing such trade policy instruments as antidumping and countervailing duties, origin marking, and safeguard measures.

\footnotetext{
* Until further decision by MAST members, no efforts will be made to collect measures under these categories from official sources. These categories have been created in order to reflect potential concerns by traders through surveys and questionnaires.
} 


\section{Classification of procedural obstacles}

\section{A:ARBITRARINESS OR INCONSISTENCY}

1. Behaviour of public officials

2. Product classification and/or valuation

3. Application of procedure, regulation, or requirement (including inconsistencies between local and national procedure or regulation)

\section{B: DISCRIMINATORY BEHAVIOUR FAVOURING SPECIFIC PRODUCERS OR SUPPLIERS}

1. Local suppliers or producers in destination market

2. Suppliers from other countries

3. Large (or small) companies

\section{C: INEFFICIENCY OR OBSTRUCTION}

1. Excessive documentation requirement

2. Strict/detailed/redundant testing, certification or labelling

3. Administrative delay (e.g. in authorisation, approval)

4. Complex clearances mechanism (e.g. several entities have to approve)

5. Short submission deadlines for required information or forms

6. Outdated procedures, (e.g. lack of automation)

Lack of resources, (e.g. understaffing, scarce equipment in destination market)

\section{D: NON-TRANSPARENCY}

1. Inadequate information on laws/regulations/registration

2. Unannounced change of procedure, regulation or requirement

3. Lack of inquiry point

4. Non-transparent government bid or reimbursement process

5. Non-transparent dispute resolution

6. Informal payment expected or required

\section{E: LEGAL ISSUES}

1. Lack of enforcement, e.g. patents, copyrights, trademarks, confidentiality

2. Inadequate due process/appeals process/dispute resolution

3. Inadequate legal infrastructure

F: UNUSUALLY HIGH FEES OR CHARGES (e.g. for stamp, testing or other services rendered) 


\section{Appendix 2.}

\section{Derivation of Market Equilibria and Welfare Measures}

This appendix provides details on the derivation of the consumer demand functions and gives the analytical expressions for the calculation of welfare effects for the different cases discussed in the main text.

The inverse demand for indifferent and concerned consumers

Recall the utility function (1):

$U_{i}\left(q_{i}, w_{i}\right)=a q_{i}-\bar{b} q_{i}^{2} / 2-I r_{i} q_{i}+w_{i}$

Maximization of (1) under the budget constraint $p q_{i}+w_{i}=y_{i}$, where $y_{i}$ denotes the income of person $i$, leads to the following inverse demand function $p=a-\bar{b} q_{i}-I \times r_{i}$. The corresponding demand for the consumer $i$ is $q_{i}(p)=\left(a-p-I \times r_{i}\right) / \bar{b}$. Aggregate demand over all consumers is then $Q=\sum_{i=1}^{N} q_{i}(p)$ leading to $Q=N(a-p) / \bar{b}-I \times \sum_{i=1}^{N} r_{i} / \bar{b}$. By assuming $b=\bar{b} / N$, inverting aggregate demand leads to the inverse demand function

$$
p^{D}(Q, I)=a-b Q-\left(I \times \sum_{i=1}^{N} r_{i}\right) / N .
$$

We assume that a proportion $\beta=N_{l} / N$ of consumers are completely indifferent to the specific characteristic, with $r_{i}=0$ for every $i=1, . ., N_{l}$. The proportion $(1-\beta)=1-N_{1} / N$ of consumers is reluctant to consume the specific characteristic and associate a damage per unit consumed equal to $r_{2}$ across all this subgroup. In this case, it is possible to divide the previous aggregate demand in two subgroup demands, with $Q_{1}^{D}(p)=\sum_{i=1}^{N_{1}} q_{i}(p)=N_{1}(a-p) / \bar{b}$ for the consumers indifferent to the negative characteristic, and $Q_{2}^{D}(p, I)=\sum_{i=1}^{\left(N-N_{1}\right)} q_{i}(p)=\left(N-N_{1}\right)\left[a-p-I \times r_{2}\right] / \bar{b}$ for the concerned consumers. With $b=\bar{b} / N, N_{l}=\beta N$ and $\left(N-N_{l}\right)=(1-\beta) N$, the respective inverse demands are given by (2) in the main text.

\section{Welfare}

For each configuration, domestic welfare is derived by considering surplus areas associated with supply and demand and externalities when they arise. 


\section{Consumption-based externalities directly linked to consumption}

Prohibitive standard (import ban)

Analytical expressions at the equilibrium under autarky (with a trade ban) are

$p^{A}=\frac{a c_{O}}{c_{O}+b M_{O}}$ for the price,

$Q^{A}=\frac{a M_{O}}{c_{O}+b M}$ for the quantity,

$P S^{A}=\int_{0}^{Q^{A}}\left[p^{A}-p_{O}^{S}(Q)\right] d Q=\frac{a^{2} c_{O} M_{O}}{2\left(c_{O}+b M_{O}\right)^{2}}$ for the overall profits of domestic producers,

$C S^{A}=\int_{0}^{Q^{A}}\left[p^{D}(Q)-p^{A}\right] d Q=\frac{a^{2} b M_{O}^{2}}{2\left(c_{O}+b M_{O}\right)^{2}}$ for the consumer's surplus,

$W^{A}=P S^{A}+C S^{A}=\frac{a^{2} M_{O}}{2 c_{O}+2 b M_{O}}$ for the welfare.

Free Trade

Analytical expressions at the equilibrium under free trade are

$p^{B}=\frac{c_{O} c_{F}\left(a-(1-\beta) r_{2}\right)}{c_{O}\left(c_{F}+b M_{F}\right)+b M_{O} c_{F}}$ for the price,

$Q^{B}=\frac{\left(c_{O} M_{F}+c_{F} M_{O}\right)\left(a-(1-\beta) r_{2}\right)}{c_{O}\left(c_{F}+b M_{F}\right)+b M_{O} c_{F}}$ for the quantity,

$P S_{O}^{B}=\int_{0}^{q_{O}^{B}}\left[p^{B}-p_{O}^{S}(Q)\right] d Q=\frac{c_{O}\left(c_{F}\right)^{2} M_{O}\left(a-(1-\beta) r_{2}\right)^{2}}{2\left[c_{O}\left(c_{F}+b M_{F}\right)+b M_{O} c_{F}\right]^{2}}$ for the overall profits of domestic

producers,

$C S_{1}^{B}=\int_{0}^{q_{1}^{B}}\left[p_{1}^{D}(Q)-p^{B}\right] d Q=\frac{\beta\left(a b\left(c_{O} M_{F}+c_{F} M_{O}\right)+c_{O} c_{F}(1-\beta) r_{2}\right)^{2}}{2 b\left[c_{O}\left(c_{F}+b M_{F}\right)+b M_{O} c_{F}\right]^{2}}$, for the indifferent

consumer's surplus,

$C S_{2}^{B}=\int_{0}^{q_{2}^{B}}\left[p_{2}^{D}(Q, 1)-p^{B}\right] d Q=\frac{(1-\beta)\left(a b\left(c_{O} M_{F}+c_{F} M_{O}\right)-r_{2}\left(b\left(c_{O} M_{F}+c_{F} M_{O}\right)+\beta c_{O} c_{F}\right)\right)^{2}}{2 b\left[c_{O}\left(c_{F}+b M_{F}\right)+b M_{O} c_{F}\right]^{2}}$, for

the reluctant consumers' surplus,

$W^{B}=P S_{o}^{B}+C S_{1}^{B}+C S_{2}^{B}$ for the domestic welfare,

$P S_{F}^{B}=\int_{0}^{q_{F}^{B}}\left[p^{B}-p_{F}^{S}(Q)\right] d Q=\frac{c_{F}\left(c_{O}\right)^{2} M_{F}\left(a-(1-\beta) r_{2}\right)^{2}}{2\left[c_{O}\left(c_{F}+b M_{F}\right)+b M_{O} c_{F}\right]^{2}}$ for the overall profits of foreign

producers. 
Free trade with a mandatory label

Analytical expressions at the equilibrium under free trade with a label are

$p_{1}^{L}=\frac{a c_{F} \beta}{c_{F} \beta+b M_{F}}$ for the first price,

$Q^{1}=\frac{a M_{F} \beta}{c_{F} \beta+b M_{F}}$ for the first quantity,

$C S_{1}^{L}=\int_{0}^{Q^{1}}\left[p_{1}^{D}(Q)-p_{1}^{L}\right] d Q=\frac{a^{2} b M_{F}^{2} \beta}{2\left(c_{F} \beta+b M_{F}\right)^{2}}$, for the indifferent consumer's surplus,

$P S_{F}^{L}=\int_{0}^{Q^{1}}\left[p_{1}^{L}-p_{F}^{S}(Q)\right] d Q=\frac{a^{2} c_{F} M_{F} \beta^{2}}{2\left(c_{F} \beta+b M_{F}\right)^{2}}$ for the overall profits of foreign producers.

$p_{2}^{L}=\frac{a c_{O}(1-\beta)}{c_{O}(1-\beta)+b M_{O}}$ for the second price,

$Q^{2}=\frac{a M_{O}(1-\beta)}{c_{O}(1-\beta)+b M_{O}}$ for the second quantity,

$C S_{2}^{L}=\int_{0}^{Q^{2}}\left[p_{2}^{D}(Q, 0)-p_{2}^{L}\right] d Q=\frac{a^{2} b M_{O}^{2}(1-\beta)}{2\left(c_{O}(1-\beta)+b M_{O}\right)^{2}}$, for the reluctant consumer's surplus,

$P S_{O}^{L}=\int_{0}^{Q^{2}}\left[p_{2}^{L}-p_{O}^{S}(Q)\right] d Q=\frac{a^{2} c_{O} M_{O}(1-\beta)^{2}}{2\left(c_{O}(1-\beta)+b M_{O}\right)^{2}}$ for the overall profits of domestic producers.

$W^{L}=P S_{o}^{L}+C S_{1}^{L}+C S_{2}^{L}$ for the domestic welfare,

Production-based externality.

Analytical expressions at the equilibrium under free trade are

$p^{G}=\frac{a c_{O} c_{F}}{c_{O}\left(c_{F}+b M_{F}\right)+b M_{O} c_{F}(1-\lambda)}$ for the expected price,

$Q^{G}=\frac{a\left(c_{O} M_{F}+c_{F}(1-\lambda) M_{O}\right)}{c_{O}\left(c_{F}+b M_{F}\right)+b M_{O} c_{F}(1-\lambda)}$ for the quantity,

$P S_{O}^{G}=\int_{0}^{q_{O}^{G}}\left[p^{G}-p_{O}^{S}(Q)\right] d Q=\frac{a^{2} c_{O}\left(c_{F}\right)^{2}(1-\lambda)^{2} M_{O}}{2\left[c_{O}\left(c_{F}+b M_{F}\right)+b M_{O} c_{F}(1-\lambda)\right]^{2}}$ for the overall expected profits of domestic producers,

$C S^{G}=\int_{0}^{Q^{G}}\left[p^{D}(Q)-p^{B}\right] d Q=\frac{b\left(a\left[c_{O} M_{F}+c_{F}(1-\lambda) M_{O}\right]\right)^{2}}{2\left[c_{O}\left(c_{F}+b M_{F}\right)+b M_{O} c_{F}(1-\lambda)\right]^{2}}$, for the consumer's surplus,

$W^{G}=P S_{O}^{G}+C S^{G}$ for the domestic expected welfare,

$P S_{F}^{G}=\int_{0}^{q_{F}^{G}}\left[p^{G}-p_{F}^{S}(Q)\right] d Q=\frac{a^{2} c_{F}\left(c_{O}\right)^{2} M_{F}}{2\left[c_{O}\left(c_{F}+b M_{F}\right)+b M_{O} c_{F}(1-\lambda)\right]^{2}}$ for the overall expected profits of

foreign producers. 


\section{Global commons externality}

Analytical expressions at the equilibrium under free trade are

$p^{E}=\frac{a c_{O} c_{F}}{c_{O}\left(c_{F}+b M_{F}\right)+b M_{O} c_{F}}$ for the price,

$Q^{E}=\frac{a\left(c_{O} M_{F}+c_{F} M_{O}\right)}{c_{O}\left(c_{F}+b M_{F}\right)+b M_{O} c_{F}}$ for the quantity,

$P S_{O}^{E}=\int_{0}^{q_{O}^{E}}\left[p^{E}-p_{O}^{S}(Q)\right] d Q=\frac{a^{2} c_{O}\left(c_{F}\right)^{2} M_{O}}{2\left[c_{O}\left(c_{F}+b M_{F}\right)+b M_{O} c_{F}\right]^{2}}$ for the overall profits of domestic

producers,

$C S^{E}=\int_{0}^{Q^{E}}\left[p^{D}(Q)-p^{B}\right] d Q=\frac{b\left(a\left(c_{O} M_{F}+c_{F} M_{O}\right)\right)^{2}}{2\left[c_{O}\left(c_{F}+b M_{F}\right)+b M_{O} c_{F}\right]^{2}}$, for the consumer's surplus,

$E X=r_{2}(1-\beta) Q^{E}=r_{2} Q_{2}^{E}=\frac{r_{2}(1-\beta) a\left(c_{O} M_{F}+c_{F} M_{O}\right)}{c_{O}\left(c_{F}+b M_{F}\right)+b M_{O} c_{F}}$, for the externality

$W^{E}=P S_{O}^{E}+C S^{E}-E X$ for the domestic welfare,

$P S_{F}^{E}=\int_{0}^{q_{F}^{E}}\left[p^{E}-p_{F}^{S}(Q)\right] d Q=\frac{a^{2} c_{F}\left(c_{O}\right)^{2} M_{F}}{2\left[c_{O}\left(c_{F}+b M_{F}\right)+b M_{O} c_{F}\right]^{2}}$ for the overall profits of foreign producers. 